\title{
The ethmoidal region of the skull of Ptilocercus lowii (Ptilocercidae, Scandentia, Mammalia) - a contribution to the reconstruction of the cranial morphotype of primates
}

\author{
I. Ruf ${ }^{1}$, S. Janßen ${ }^{2}$, and U. Zeller ${ }^{2}$ \\ ${ }^{1}$ Senckenberg Forschungsinstitut und Naturmuseum Frankfurt, Abteilung Paläoanthropologie und \\ Messelforschung, Senckenberganlage 25, 60325 Frankfurt am Main, Germany \\ ${ }^{2}$ FG Spezielle Zoologie, Lebenswissenschaftliche Fakultät, Albrecht Daniel Thaer-Institut für Agrar- und \\ Gartenbauwissenschaften, Humboldt-Universität zu Berlin, Ziegelstrasse 5-9, 10117 Berlin, Germany \\ Dedicated to Hans-Jürg Kuhn on the occasion of his 80th birthday.
}

Correspondence to: I. Ruf (irina.ruf@senckenberg.de)

Received: 17 June 2015 - Revised: 6 September 2015 - Accepted: 7 September 2015 - Published: 25 September 2015

\begin{abstract}
The ethmoidal region of the skull houses one of the most important sense organs of mammals, the sense of smell. Investigation of the ontogeny and comparative anatomy of internal nasal structures of the macrosmatic order Scandentia is a significant contribution to the understanding of the morphotype of Scandentia with potential implications for our understanding of the primate nasal morphological pattern. For the first time perinatal and adult stages of Ptilocercus lowii and selected Tupaia species were investigated by serial histological sections and high-resolution computed tomography $(\mu \mathrm{CT})$, respectively. Scandentia show a very common olfactory turbinal pattern of small mammals in having two frontoturbinals, three ethmoturbinals, and one interturbinal between the first and second ethmoturbinal. This indicates a moderately developed sense of smell (moderately macrosmatic). The observed septoturbinal is probably an apomorphic character of Scandentia. A general growth in length occurs during postnatal ontogeny; thus the adult ethmoidal region is proportionally longer compared to the rest of the skull. Throughout ontogeny Ptilocercus has a proportionally longer nasal cavity than Tupaia. Major differences exist between Ptilocercus and Tupaia in regard to the proportions of the nasal cavity which correlate with the position of the orbits. Compared to Tupaia, Ptilocercus shows more anteriorly oriented orbits and has a proportionally longer nasal capsule than Tupaia and based on anatomy probably a higher level of olfactory discrimination. Furthermore, Ptilocercus has a platybasic skull base that resembles a derived feature of Ptilocercidae. In contrast, Tupaia has a distinct septum interorbitale leading to a tropibasic skull, a pattern that is a plesiomorphic character of Tupaiidae and Scandentia in general. This finding helps us to understand the septum interorbitale pattern in Primates. Our results indicate that differences among the investigated Scandentia species are correlated with adaptations to foraging and behavioural biology.
\end{abstract}

\section{Introduction}

The ethmoidal region of the mammalian skull reveals a significant contribution to the understanding of mammalian ontogeny, evolution, phylogeny, and functional anatomy (e.g. Paulli, 1900a, b, c; Voit, 1909; Reinbach, 1952a, b; Kuhn, 1971; Kuhn and Zeller, 1987; Maier, 1991, 1993a; Craven et al., 2007, 2010; Macrini, 2012; Ruf, 2014; Ruf et al., 2014).
Being part of the chondrocranium it is completely cartilaginous in early ontogenetic stages. The cavum nasi inside is anteriorly limited by the cupula nasi anterior, dorsally by the tectum nasi and lamina cribrosa, laterally by the paries nasi, posteriorly by the cupula nasi posterior, and ventrally by the solum nasi (lamina transversalis anterior, paraseptal cartilages, and lamina transversalis posterior). The paries nasi of the pars lateralis and pars posterior gives rise to most 
of the olfactory turbinals and is therefore also called paries conchalis. The septum nasi divides the nasal cavity in symmetrical halves and separates the paraseptal spaces. During postnatal ontogeny the cartilaginous ethmoidal structures undergo a significant transformation caused by degeneration, ossification and replacement: the cupula nasi anterior and adjacent structures as well as parts of the paraseptal cartilages remain cartilaginous; the turbinals become completely ossified except for the marginoturbinal, atrioturbinal, and in certain species the anterior portions of the maxillo- and nasoturbinal; the tectum nasi, paries nasi, and parts of the paraseptal cartilages become resorbed and replaced by dermal bones (e.g. Voit, 1909; Reinbach, 1952a, b; Zeller, 1987).

The nasal cavity of mammals is unique in housing a distinct number of complex conchae that are supported by bony lamellae, the turbinals (or turbinates) and has the two-fold function of thermoregulation and olfaction (Paulli, 1900a, b, c; Hillenius, 1992; Kemp, 2006). The oldest known ossified remnants of turbinals are described in the advanced nonmammaliaform cynodont Brasilitherium riograndensis and can be dated back into the Late Triassic (Ruf et al., 2014). The anteriormost turbinals (in particular the maxilloturbinal, anterior portion of nasoturbinal) and in many species the anterior process of the first ethmoturbinal are covered by respiratory epithelium for warming and moistening the inspired air whereas the posterior turbinals (frontoturbinals, ethmoturbinals, interturbinals), the semicircular crista or lamina as well as the posterodorsal part of the nasal septum are covered by olfactory epithelium that carries the olfactory receptors of the first cranial nerve; the distribution of the olfactory epithelium differs among species and depends on their macrosmatic level (Le Gros Clark, 1951; Ruf, 2004; Rowe et al., 2005; Smith et al., 2007, 2014a; Eiting et al., 2014; Van Valkenburgh et al., 2014b).

For more than a century investigations of internal nasal structures, in particular the turbinals, were based on histological serial sections and therefore restricted to prenatal and early postnatal stages due to technical limitations. During this period a tremendous number of excellent morphological descriptions were published that cover almost all mammalian orders as well as some other amniote taxa (e.g. Gaupp, 1900; Voit, 1909; de Beer, 1929; Reinbach, 1952a, b; Starck, 1960; Maier, 1980; Kuhn, 1971; Ruf, 2004). Most of these works focused on comparative descriptions and were mostly restricted to one or a few species. Though they provide significant contributions to the understanding of the early ontogeny of the mammalian nose and detecting general homologies, in many cases the incorporation of adult characters was not possible (Maier, 1993a). However, this is due to the fact that in postnatal ontogeny the turbinal pattern may change significantly by ossification, outgrowth of additional small lamellae on the turbinals (so-called epiturbinals), and additional interturbinals (e.g. Ruf, 2014). Only very few publications have dealt with juvenile or adult crania in this early stage of research on ethmoidal anatomy. The most important one may be the work of Paulli (1900a, b, c), who investigated the adult turbinal and nasal sinus pattern in about 100 species covering several mammalian orders. However, he introduced a different nomenclature (ectoturbinals, endoturbinals) simply by numbering the turbinals and without any consideration of ontogenetic origin, topography, and evolution of the structures, which clearly hinders detecting homologies among different species (see Ruf, 2014, for more details).

Thanks to modern non-invasive imaging techniques, e.g. high-resolution computed tomography $(\mu \mathrm{CT})$, research on the ethmoidal region has changed dramatically in recent years. Adult specimens can now be investigated to elucidate the three-dimensional architecture of the internal nasal structures (e.g. Clifford and Witmer, 2004; Rowe et al., 2005; Van Valkenburgh et al., 2004, 2011; Craven et al., 2007, 2010; Macrini, 2012; Maier and Ruf, 2014; Ruf, 2014). A recently published supplement to The Anatomical Record is an outcome of a symposium dealing with the vertebrate nose that took place at the 10th International Congress of Vertebrate Morphology in Barcelona in 2013 and demonstrates the renaissance of research on the ethmoidal region especially in primates (see Van Valkenburgh et al., 2014a). However, comprehensive comparative studies of the prenatal to adult turbinal skeleton of the putative sister group of primates, the Scandentia (tree shrews), to elucidate ontogenetic transformations, systematic relationships, and evolutionary scenarios are still missing.

Based on recent morphological and phylogenetic studies the order Scandentia comprises two families: Tupaiidae (Tupaia, Dendrogale, Urogale, Anathana) and the monospecific Ptilocercidae (Ptilocercus lowii, pen-tailed tree shrew) (Helgen, 2005). Previously both families were classified as subfamilies within Tupaiidae (Wilson, 1993; McKenna and Bell, 1997). Ptilocercus holds a key position as it might resemble the basal clade within extant Scandentia representing the scandentian ancestral morphotype in many respects apart from several autapomorphic unique features (Olson et al., 2004; Sargis, 2007; Wible, 2009; Roberts et al., 2011).

Scandentia are nested within the major placental clade Euarchontoglires. While Rodentia and Lagomorpha are distinct sister groups forming the cohort Glires, the sister-group relationships among the remaining three orders (Dermoptera, Scandentia, Primates) are still discussed based on molecular data (Murphy et al., 2001; Springer et al., 2003; Nishihara et al., 2006; Bininda-Emonds et al., 2007). According to Meredith et al. (2011), a molecular supertree analysis combined with relaxed molecular clocks, Scandentia are the sister group of Glires. A recent study of O'Leary et al. (2013) is based on morphological and palaeontological data and clearly supports the sister-group relationship of Scandentia and Dermoptera to form the clade Sundatheria. However and although the phylogenetic position of Scandentia is still under discussion, this taxon is still essential for understanding cranial anatomy, evolutionary transformations, and systemat- 
ics not only of Primates but also of the entire euarchontogliran clade.

Anatomy and development of Scandentia has been investigated mainly in Tupaia but also in Ptilocercus lowii in regard of skeletal and soft tissue anatomy, craniogenesis, embryogenesis, and placentation (e.g. Lyon Jr., 1913; Le Gros Clark, 1925, 1926; Spatz, 1964; Kuhn and Schwaier, 1973; Zeller, 1983, 1986a, b; Kuhn and Liebherr, 1988; Wible and Zeller, 1994; Funke and Kuhn, 1998; Wible, 2009, 2011). Ontogeny of internal nasal structures is only known from Tupaia belangeri (Zeller, 1983, 1987), Tupaia glis (Spatz, 1964), and Tupaia javanica (Henckel, 1928; Spatz, 1964). A detailed PhD thesis of the chondrocranium of a fetal Ptilocercus including the ethmoidal region was conducted by Janßen (1993). The adult internal rostrum pattern of Ptilocercus has been investigated by LeGros Clark (1926) and Wible (2011). However, due to the application of an inappropriate terminology (see comment below), certain misinterpretations of the turbinal skeleton arose in both publications. Furthermore, the investigation of Wible (2011) is solely based on macroscopic preparation of the nasal cavity, which hinders a detailed understanding of the three-dimensional arrangement of the turbinal skeleton in many respects.

Here we provide the first description of an ontogenetic transformation of the nasal cavity from fetal to adult stage in Ptilocercus lowii. The adult pattern is compared to an adult Tupaia sp. whose turbinal skeleton has been briefly mentioned in Ruf (2014). Significantly different character patterns in early ontogenetic stages of the already investigated Tupaia species are considered based on literature (see above). However, we should point out that differences in size and shape may be affected by heterochronic growth in the respective species of Tupaia and therefore should not be overestimated. Finally, our results are an important contribution to cranial anatomy and ontogeny of Euarchontoglires and help to elucidate the primate ancestral morphotype.

\section{Material and methods}

In order to elucidate the prenatal ontogeny an embryo of Ptilocercus lowii (no. Ib, $30 \mathrm{~mm}$ CRL, $17.7 \mathrm{~mm} \mathrm{HL}$ ) from the Hubrecht Collection, Utrecht (the Netherlands), and currently located at the Museum für Naturkunde zu Berlin (Germany) was investigated by histological serial sections. These sections $(10 \mu \mathrm{m})$ were used to create a three-dimensional plate model according to Born (1883, modified according to Zeller, 1983) (Figs. 1, 2); for details see Janßen (1993). Drawings of selected slices have been prepared based on enlarged photomicrographs (Figs. 5, 6). In addition, histological serial sections of several dated fetal stages of Tupaia belangeri from the Hans-Jürg Kuhn collection (Göttingen, Germany), now part of the Senckenberg collection (Frankfurt am Main, Germany) and currently located at Medizinische Fakultät Universität Münster (Germany), were investigated for comparison (see Zeller, 1983, 1987, for details). The focus was on a 34-day-old fetus. In addition, data from Spatz (1964) on a neonate Tupaia glis were also used for comparison. As all these Tupaia specimens have been imported from Bangkok and the Tupaia belangeri-chinensis group is very closely related to Tupaia glis, it is likely that all specimens represent the same species (see Zeller, 1983, for further details, Wible, 2011).

An adult specimen of Ptilocercus lowii (ZMB 3992) from the collection of the Museum für Naturkunde $\mathrm{zu}$ Berlin (Germany) was investigated with the local $\mu \mathrm{CT}$ scanner nanotom (GE phoenix $\mid \mathrm{x}-$ ray); voxel size (resolution) is $0.01991 \mathrm{~mm} \times 0.018991 \mathrm{~mm} \times 0.018991 \mathrm{~mm}$. In addition the cleaned skull of an adult Tupaia sp. (collection W. Maier, Tübingen) was scanned with the $\mu \mathrm{CT}$ device v|tome|x s (GE phoenix|x-ray) housed in the Steinmann-Institut für Geologie, Mineralogie und Paläontologie, Universität Bonn, Germany; voxel size is $0.05865 \mathrm{~mm} \times 0.05865 \mathrm{~mm} \times 0.05865 \mathrm{~mm}$. Virtual threedimensional reconstructions of the turbinal skeleton were made with the software Avizo 7.1 (FEI) (Figs. 3, 4).

Due to the fact that $\mu \mathrm{CT}$ scans reveal predominantly hard tissues of the body, the present study refers to ossified skeletal structures of the ethmoidal region (Figs. 7-15). However, a detailed description of the cranial soft tissue and cartilaginous structures in a Ptilocercus fetus is presented in Janßen (1993).

\section{Terminology}

The anatomical terminology was used according to Voit (1909), Reinbach (1952a, b), and Ruf (2014). Most recent investigations (e.g. Wible, 2011) are still based on the terminology mainly introduced by Paulli (1900a, b, c) in which turbinals are simply numbered and divided into ectoturbinals (fronto- and interturbinals) and endoturbinals (ethmoturbinals and erroneously the lamina semicircularis). Thus, non-homologous structures and those with different ontogenetic origin are consequently homologized which is a limiting factor for the comparison of turbinal patterns among investigated species (Ruf, 2014). This problem is mainly raised by the lack of knowledge of prenatal and early postnatal ontogeny of internal nasal structures in most species.

The terminology of frontoturbinals used in the present work is different from Spatz (1964), Zeller (1983, 1987), and Janßen (1993) as the homology especially of frontoturbinals is still problematic. Therefore, here we use the developmental pattern (Kuhn and Zeller, 1987) to define the specific frontoturbinals because topographic criteria are insufficient due to ontogenetic variations.

\section{Comparative description}

The ethmoidal region of the Ptilocercus fetus is still completely cartilaginous and resembles approximately the same 
A

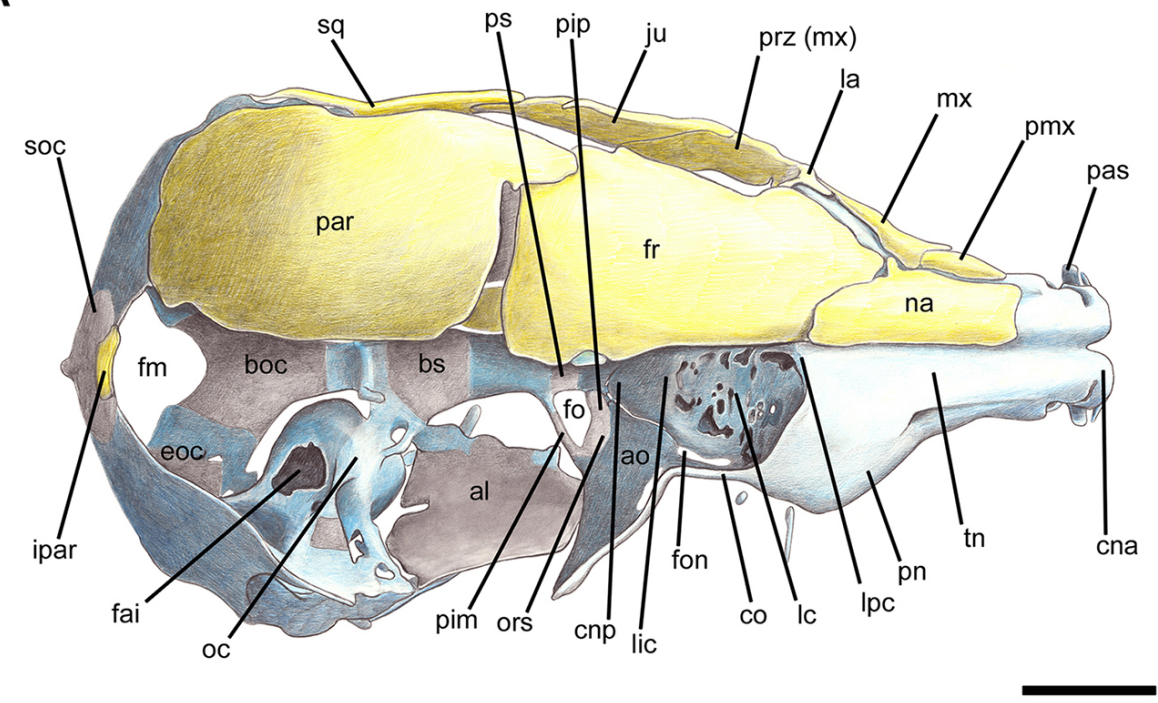

B

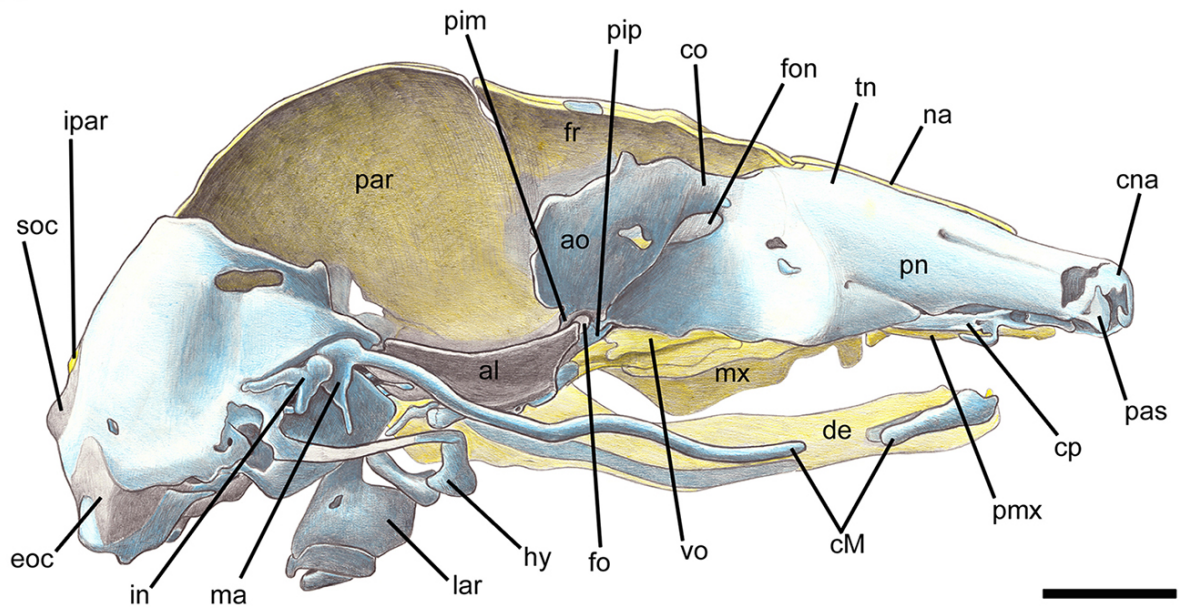

Figure 1. Three-dimensional plate model of the cranium of the fetal Ptilocercus lowii (30 mm CRL): (a) dorsal view, (b) right lateral view. Reconstruction of dermal bones is restricted to left side. Cartilage is drawn in blue, dermal bones in yellow, and endochondral bone in grey. Abbreviations: al, alisphenoid; ao, ala orbitalis; boc, basioccipital; bs, basisphenoid; cM, cartilago Meckeli; can, cupula nasi anterior; cnp, cupula nasi posterior; co, commissura orbitonasalis; cp, cartilago paraseptalis; de, dentary; eoc, exoccipital; fai, foramen acusticum internum; fm, foramen magnum; fo, foramen opticum; fon, fissura orbitonasalis; fr, frontal; hy, hyoid; in, incus; ipar, interparietal; ju, jugal; la, lacrimal; lar, larynx; lc, lamina cribrosa; lic, lamina infracribrosa; lpc, limbus praecribrosus; ma, malleus; mx, maxilla; na, nasal; oc, otic capsule; ors, orbitosphenoid; par, parietal; pas, processus alaris superior; pim, pila metoptica; pip, pila praeoptica; pmx, premaxilla; pn, paries nasi; prz, processus zygomaticus; ps, presphenoid; soc, supraoccipital; sq, squamosal; tn, tectum nasi; vo, vomer. Scale bars equal 2 mm.

developmental stage as a 38-day-old fetus of Tupaia belangeri (Zeller, 1983, 1987).

\subsection{Extension and expansion of nasal cavity}

Head length and cranial length of the investigated Ptilocercus fetus are 17.7 and $16.0 \mathrm{~mm}$, respectively (Fig. 1). The length of the nasal capsule is $7.7 \mathrm{~mm}$, its maximum width $5.0 \mathrm{~mm}$ and its maximum height $2.3 \mathrm{~mm}$. Length, height, and width of the nasal capsule amount to $5.9,5.1$, and $2.6 \mathrm{~mm}$ in a fetal Tupaia belangeri (34 days), and 8.3, 5.2, and $3.1 \mathrm{~mm}$ in a neonate Tupaia glis. In order to detect the length of the nasal capsule relative to the entire skull length the ratio of basicranial length posterior of the cupula nasi posterior to ethmoidal region was calculated. This ratio is $1: 1.2$ in Ptilocercus and $1: 0.9$ in both Tupaia specimens. Thus the prenatal nasal capsule of Ptilocercus is longer than that of Tupaia (Fig. 2). 

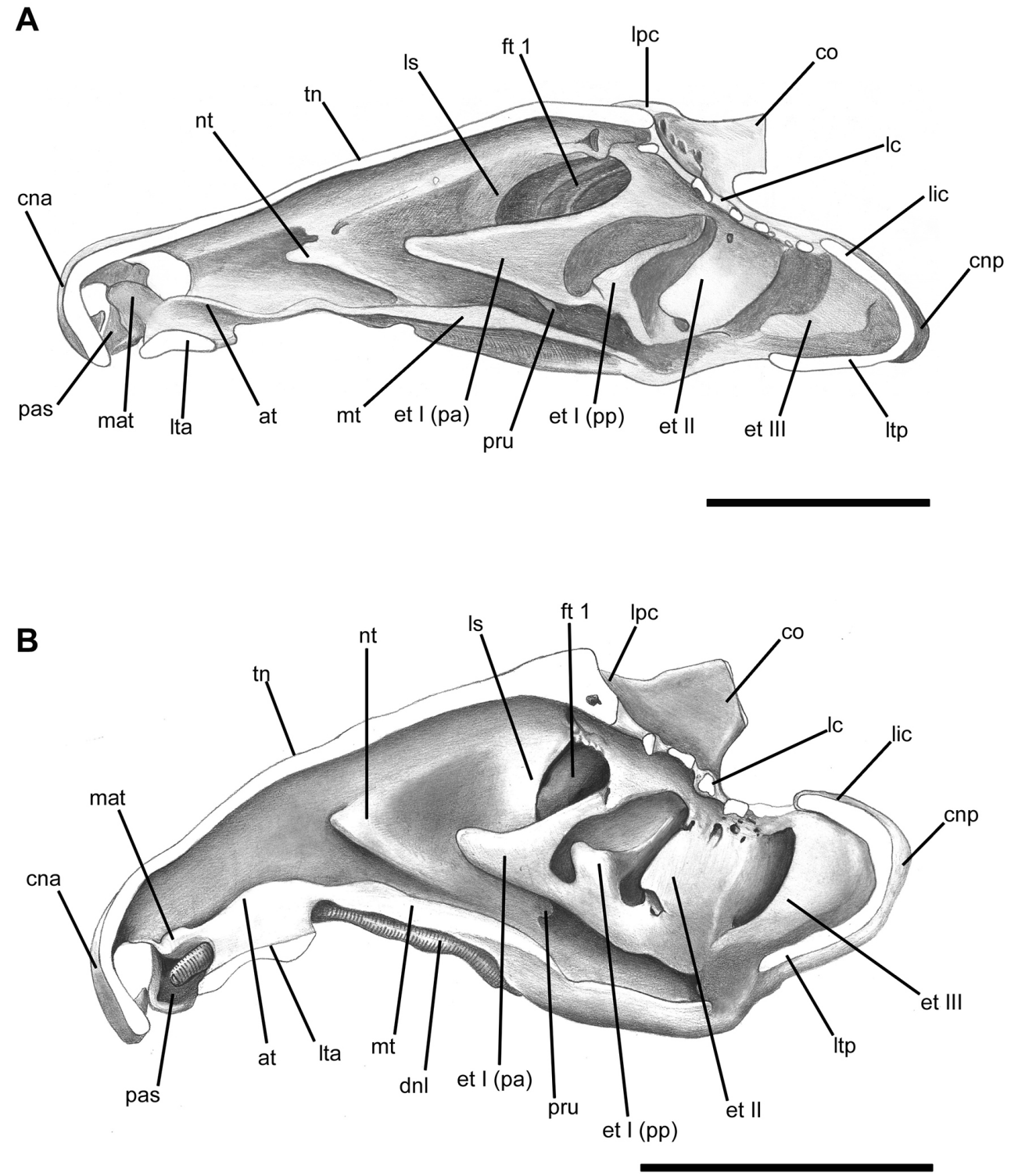

Figure 2. Three-dimensional plate models of the right fetal nasal capsule of (a) Ptilocercus lowii (30 mm CRL) and (b) Tupaia belangeri (34 days) in medial view (b). Abbreviations: at, atrioturbinal; can, cupula nasi anterior; cnp, cupula nasi posterior; co, commissura orbitonasalis; dnl, ductus nasolacrimalis; et I, II, III, ethmoturbinal I, II, III; ft 1, frontoturbinal 1; lc, lamina cribrosa; lic, lamina infracribrosa; lpc, limbus praecribrosus; 1s, lamina semicircularis; lta, lamina transversalis anterior; ltp, lamina transversalis posterior; mat, marginoturbinal; mt, maxilloturbinal; nt, nasoturbinal; pa, pars anterior; pas, processus alaris superior; pp, pars posterior; pru, processus uncinatus; tn, tectum nasi. Scale bars equal $2 \mathrm{~mm}$.

In the adult Ptilocercus the ethmoidal region extends posteriorly between the orbits and reaches the level of the postorbital bar (Fig. 3a, c). It measures $20.70 \mathrm{~mm}$ and the basicranium behind the nasal cavity is $14.26 \mathrm{~mm}$ long. Thus, the ratio is $1: 1.45$. In contrast the ethmoidal region of Tupaia ends in the anterior third of the orbit (Fig. 3b, d). The length of the nasal cavity of Tupaia is $25.10 \mathrm{~mm}$; the basicranium behind is $18.36 \mathrm{~mm}$. Thus, the ratio of basicranium posterior to the ethmoidal region to nasal cavity length is $1: 1.37$. Though the nasal cavity becomes proportionally longer during postnatal growth, it still remains shorter but wider in Tupaia (Figs. 3, 4). In contrast, in Ptilocercus it becomes evident that the orbits narrow the posterior nasal space (Figs. 3c, d, 4e, f, 9, 10, $11,12)$.

\subsection{Septum nasi and septum interorbitale}

In fetal stages the septum nasi is a continuous vertical lamina that connects the cupula nasi anterior and the cupula nasi posterior. Dorsally it is fused to the tectum nasi, ventrally it 


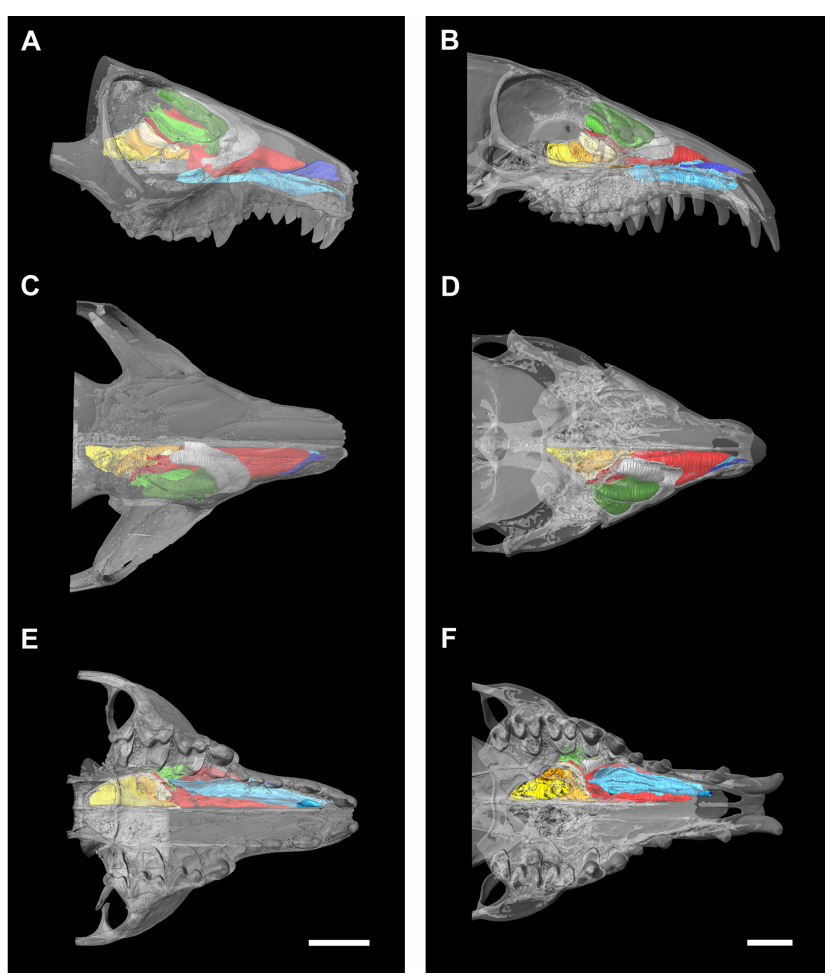

Figure 3. Virtual three-dimensional models of the adult rostrum of (a, c, e) Ptilocercus lowii (ZMB 3992) and (b, d, f) Tupaia sp. (collection W. Maier): (a) and (b) left lateral view, (c) and (d) dorsal view, (e) and (f) ventral view. Skull bones are made translucent to allow view on reconstructed turbinal skeleton highlighted in the same colour code as in Fig. 4. Scale bars equal $5 \mathrm{~mm}$.

is continuous with the lamina transversalis anterior in many species. The free ventral rim is inflated as also observed in the investigated Scandentia (Fig. 5). In lateral view the septum nasi resembles a triangle with its largest height just in front of the lamina cribrosa. During postnatal ontogeny the septum nasi becomes mostly ossified and part of the ethmoid bone in adult stages. Posteriorly its ventral edge fuses to the vomer. The alae vomeris form lateral wings on the septum nasi. However, the anterior portion correlated with the flexible anterior nasal cartilages remains cartilaginous throughout the entire lifetime (see Zeller, 1983, 1987). This general fetal as well as adult pattern can also be observed in our investigated Scandentia.

In the pars anterior of the fetal Ptilocercus the septum nasi shows a so-called septoturbinal, a longitudinal prominent ridge (Fig. 5b). Anteriorly, the ossified septum nasi rises on the level of the upper second incisor; its ventral inflation is hollowed and restricted to the pars anterior (Fig. 7c). The septoturbinal is still present in the adult Ptilocercus and represents a hollow longitudinal bulge on the dorsal part of septum nasi (Fig. 7c, e). Two small and short septoturbinal-like ridges approach the nasoturbinal from ventrally and fuse to the latter. Neither a distinct crista galli nor a spina meseth- moidalis is present in the investigated ontogenetic stages (Figs. 6, 10a, 11a).

In the investigated perinatal stages of Tupaia no septoturbinal is evident though the septum nasi of a neonate $T u$ paia glis shows a conspicuous thickened ridge (Spatz, 1964; Zeller, 1983, 1987). The investigated adult specimen clearly shows a very long septoturbinal that runs from the pars anterior far into the pars posterior and almost resembles the pattern of Ptilocercus (Figs. 7d, f, 8b, d, 9b, 10b, 11b, 12b).

According to Spatz (1964) Tupaia javanica develops a short and low but distinct crista galli in late prenatal ontogeny. In contrast to Ptilocercus the septum nasi and tectum nasi of Tupaia form a caudally oriented spine right at the anterior border of the lamina cribrosa, the so-called spina mesethmoidalis. This spine is already very prominent in prenatal stages (Spatz, 1964; Zeller, 1983, 1987) but fused to the frontals and therefore not identifiable anymore.

At the posterior end of the ethmoidal region in all investigated stages of Tupaia the septum nasi continues into a septum interorbitale that separates the orbits (Fig. 15d). This is not the case in Ptilocercus, which has a flat trabecular plate and basicranium in this region (Fig. 15c).

\subsection{Lamina cribrosa}

The lamina cribrosa is the posterior roof of the nasal cavity. Its anterior border is the limbus praecribrosus. Laterally the lamina cribrosa is limited by the limbus paracribrosus and posteriorly by the limbus postcribrosus of the lamina infracribrosa (Fig. 2). All these borders become ossified and incorporated into the dermal bones of the osteocranium.

In the fetal Ptilocercus the lamina cribrosa is still cartilaginous and trapeziform. Its greatest width is along the limbus praecribrosus and it is ventrally concave (Figs. 1a, 2a, 6). This concavity is correlated with the space needed by the bulbus olfactorius. In contrast the lamina cribrosa of a fetal Tupaia belangeri and a neonate Tupaia glis is almost triangular (Spatz, 1964; Zeller, 1983, 1987). The convexity of the lamina cribrosa is not as deep as in Ptilocercus (Fig. 2b), but the depth increases during ontogeny (Zeller, 1983, 1987). The limbus postcribrosus is more pronounced in Ptilocercus than in Tupaia.

In the adult stages of Ptilocercus and Tupaia the concavity is still present though restricted to the anterior part in the former (Figs. 10a, 11-14, 15a, c).

The lamina cribrosa shows numerous foramina olfactoria that are the pathways for the fila olfactoria (cranial nerve I). Their number increases during ontogeny while their size decreases. This trend is also observable in the investigated Scandentia and well documented in the ontogenetic series of Tupaia belangeri (Zeller, 1983, 1987). In the adult Scandentia the posterior section of the lamina cribrosa above ethmoturbinal III shows no foramina and therefore corresponds to the lamina infracribrosa; this area appears to be larger in Ptilocercus. 

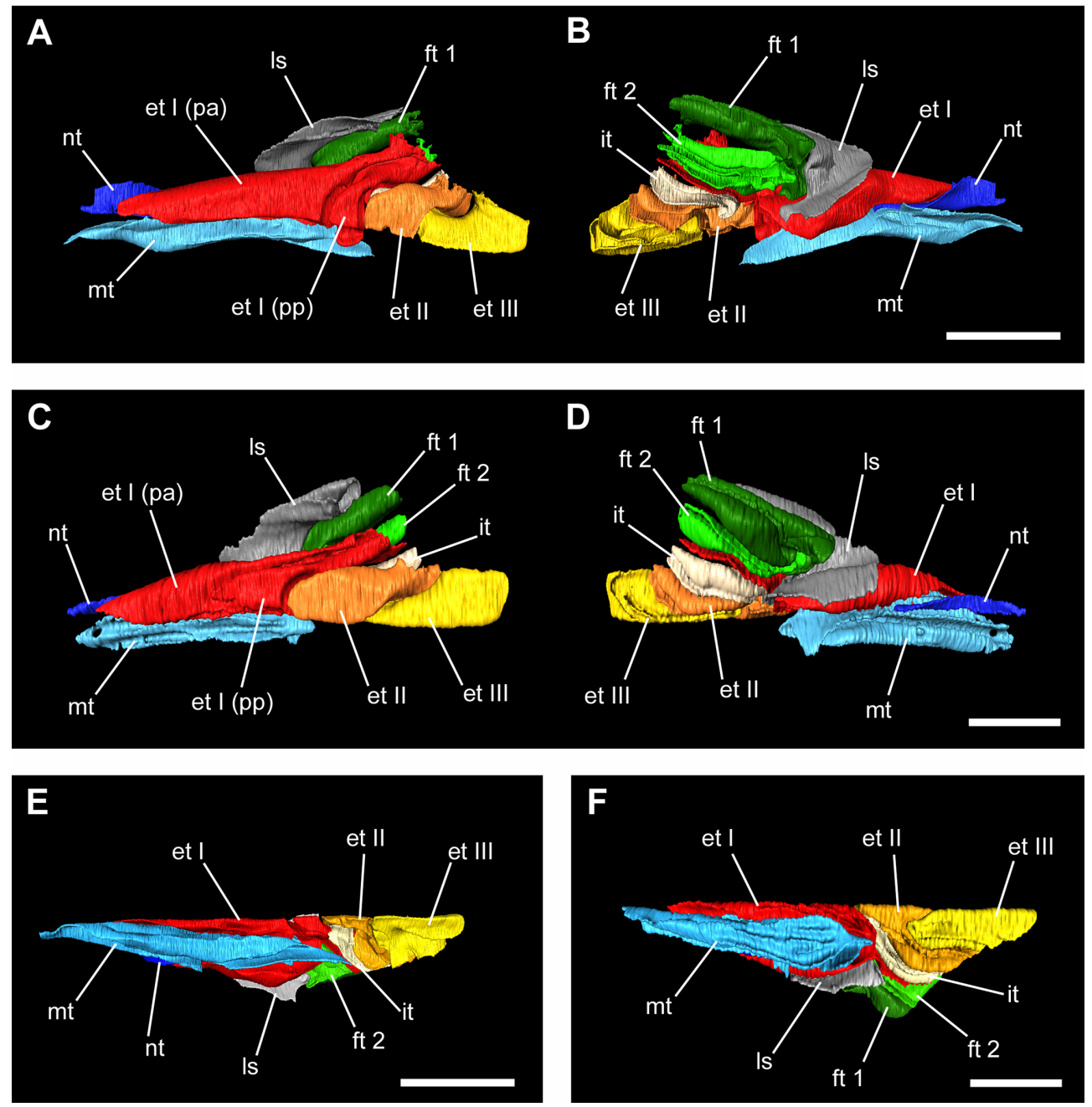

Figure 4. Virtual three-dimensional models of the right adult turbinal skeleton of (a, b, e) Ptilocercus lowii (ZMB 3992) and (b, c, f) Tupaia sp. (collection W. Maier): (a) and (c) medial view, (b) and (d) lateral view, (e) and (f) ventral view. Abbreviations: et I, II, III, ethmoturbinal I, II, III; ft 1, 2, frontoturbinal 1, 2; it, interturbinal; ls, lamina semicircularis; mt, maxilloturbinal; nt, nasoturbinal; pa, pars anterior; pp, pars posterior. Scale bars equal $5 \mathrm{~mm}$.

\subsection{Pars anterior of nasal cavity}

The anterior part of the nasal cavity houses several turbinals, most of which are organized in a ventral row. The anteriormost turbinal, the marginoturbinal, arises from the anterior nasal cupula and is continuous with the atrioturbinal. All these structures persist postnatally as cartilage. Thus, they are not visible in the $\mu \mathrm{CT}$ scan of the adult specimens and therefore are not described here.

The maxilloturbinal of Ptilocercus continues the ventral turbinal row as a simple medial infolding of the cartilaginous sidewall of the nasal cavity, the so-called paries nasi (Figs. 2a, 5, 6b). In the adult the roof and sidewalls of the cartilaginous nasal capsule no longer exist and are functionally replaced by the dermal bones; the maxilloturbinal appears to be completely ossified. The maxilloturbinal anteriorposterior extension is comparable to that of the first turbinal, and both are the longest turbinals in Ptilocercus (Fig. 4a, b). The ossified turbinal projects from the premaxilla on the level of the first upper incisor and ends on the level of the second upper molar on the maxilla. The base (or root) of the maxilloturbinal curves smoothly from the sidewall of the nasal cavity to the nasal floor in the posterior part of the nasal cavity. Anteriorly and posteriorly the maxilloturbinal of Ptilocercus resembles a straight lamella that projects into the nasal cavity. In between it shows a complicated double scroll; its dorsal portion is embraced by ethmoturbinal I (Figs. 4a, b, 7a, c, e, 8a, c, 9a).

In general the maxilloturbinal pattern of Tupaia is quite similar to Ptilocercus (Figs. 2b, 7b, d, f, 8b). However, the adult maxilloturbinal is proportionally shorter only about two-thirds of the total length of the first ethmoturbinal due to the greater absolute length of the latter (Fig. 4c, d). The 
A

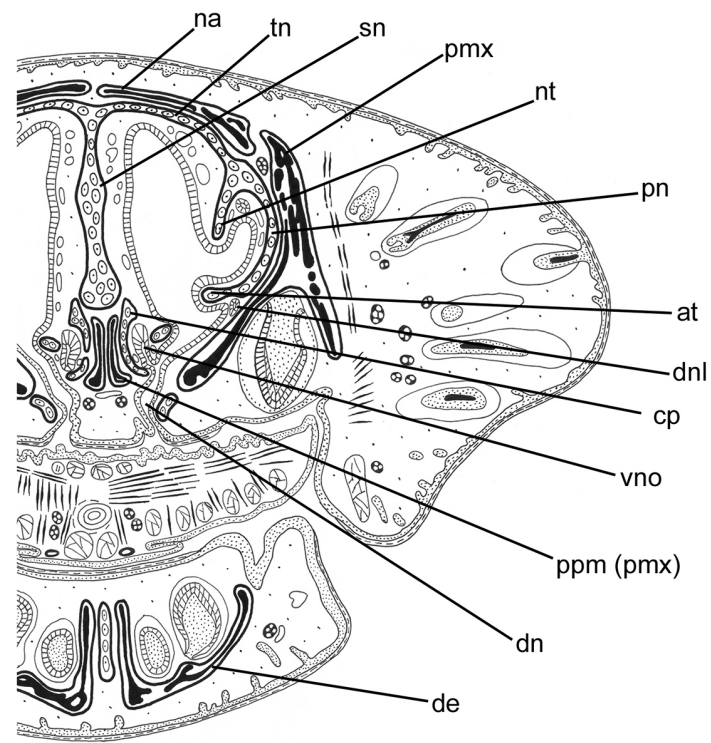

B

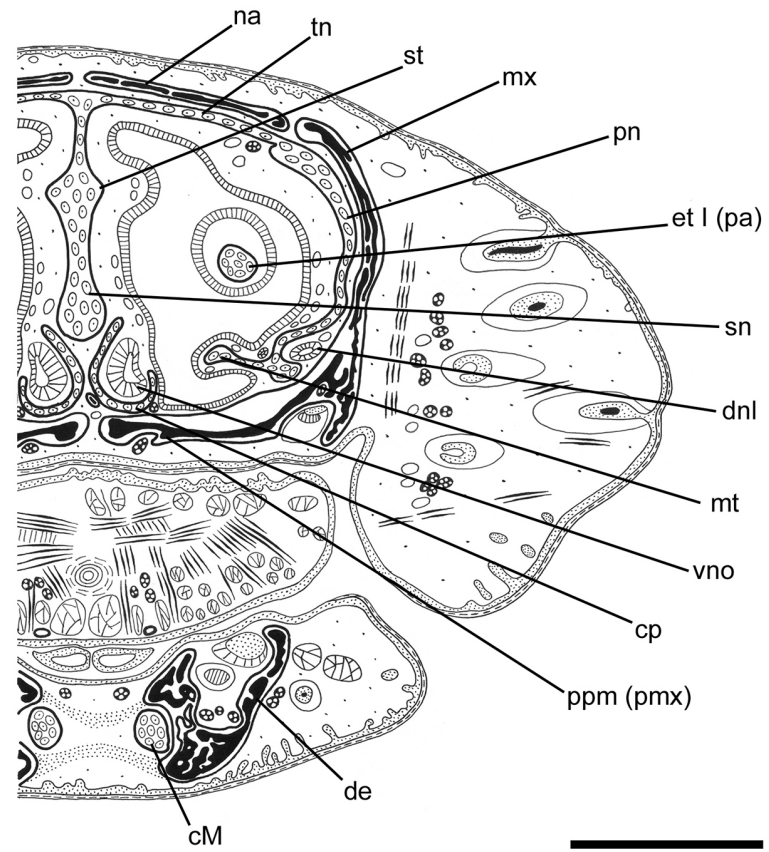

Figure 5. Drawings of histological cross sections through the pars anterior of the fetal nasal cavity from anterior (a) to posterior (b) of Ptilocercus lowii (30 mm CRL). Abbreviations: at, atrioturbinal; cM, cartilago Meckeli; cp, cartilago paraseptalis; de, dentary; dn, ductus nasopalatinus; dnl, ductus nasolacrimalis; et I, ethmoturbinal I; mt, maxilloturbinal; mx, maxilla; na, nasal; nt, nasoturbinal; pa, pars anterior; pmx, premaxilla; pn, paries nasi; ppm, processus palatinus medialis; sn, septum nasi; st, septoturbinal; tn, tectum nasi; vno, vomeronasal organ. Scale bars equal $2 \mathrm{~mm}$.

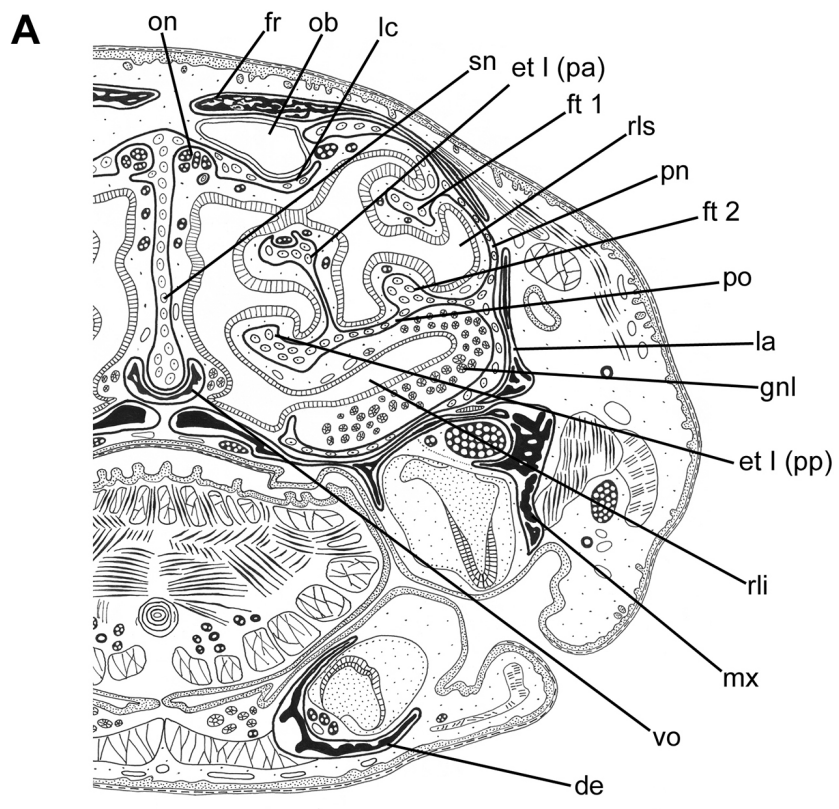

B

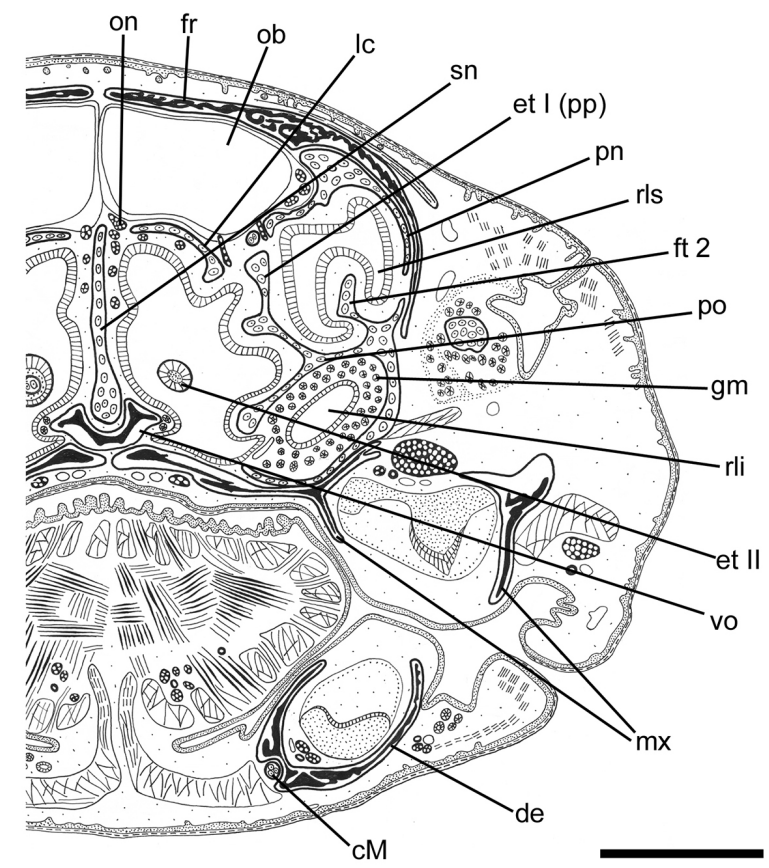

Figure 6. Drawings of histological cross sections through the pars lateralis and posterior of the fetal nasal cavity from anterior (a) to posterior (b) of Ptilocercus lowii (30 mm CRL). Abbreviations: cM, cartilago Meckeli; de, dentary; et I, II, ethmoturbinal I, II; fr, frontal; ft 1, 2, frontoturbinal 1, 2; gm, glandula maxillaris; gnl, glandula nasi lateralis; la, lacrimal; lc, lamina cribrosa; mx, maxilla; ob, olfactory bulb; on, olfactory nerves; pa, pars anterior; pn, paries nasi; po, pars obtecta (paries conchalis); pp, pars posterior; rli, recessus lateralis inferior; rls, recessus lateralis superior; sn, septum nasi; vo, vomer. Scale bars equal $2 \mathrm{~mm}$. 

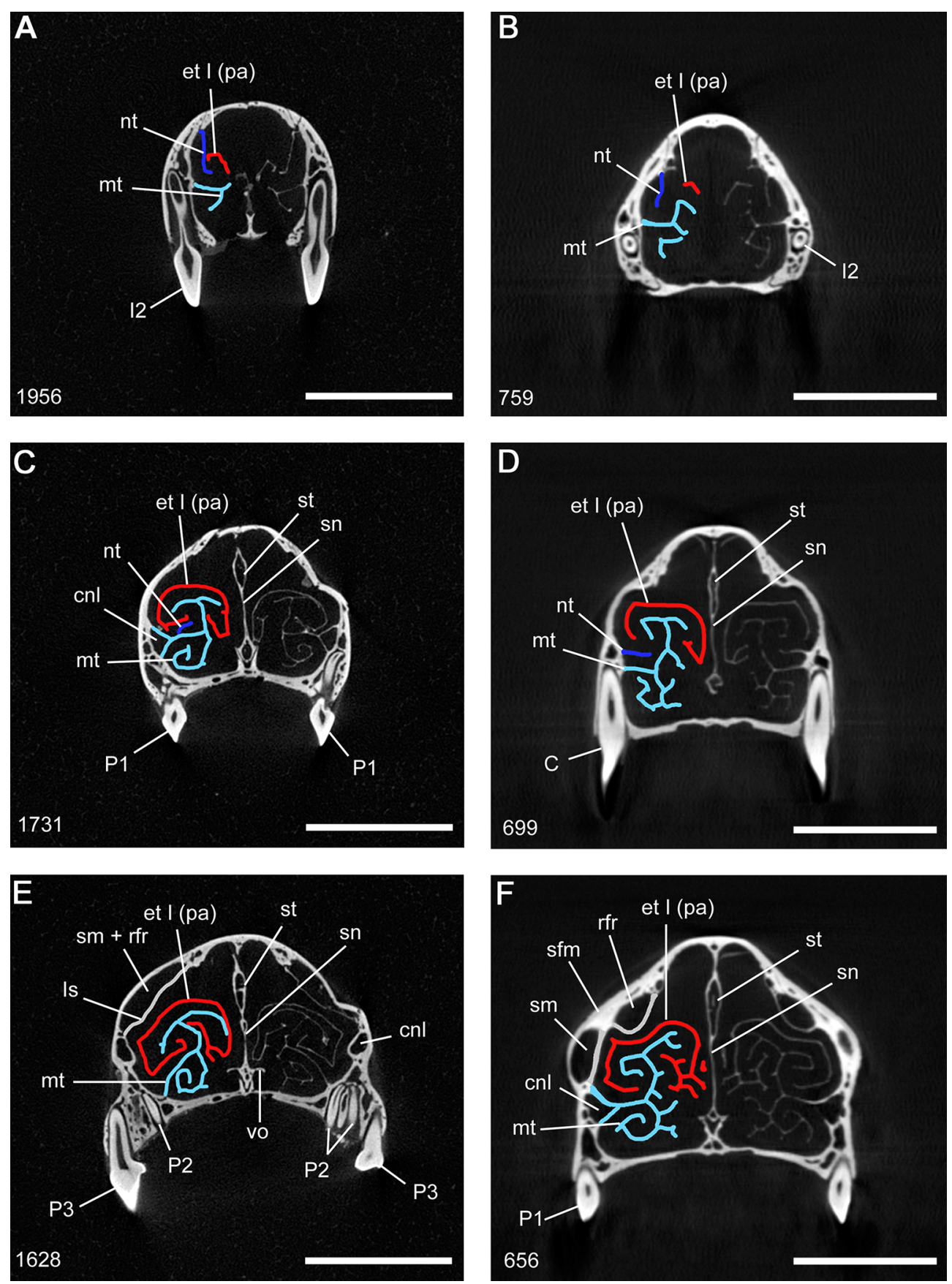

Figure 7. $\mu \mathrm{CT}$ cross-section images of the pars anterior of the adult rostrum from anterior to posterior of (a, c,e) Ptilocercus lowii (ZMB 3992) and (b, d, f) Tupaia sp. (collection W. Maier). Numbers in figures refer to number of original $\mu \mathrm{CT}$ slices. Abbreviations: C - upper canine; cnl, canalis nasolacrimalis; et I, ethmoturbinal I; I2, upper incisor 2; 1s, lamina semicircularis; mt, maxilloturbinal; nt, nasoturbinal; P1, 2, 3, upper premolar 1, 2, 3; pa, pars anterior; rfr, recessus frontalis; sfm, septum frontomaxillare; sm, sinus maxillaris; sn, septum nasi; st, septoturbinal; vo, vomer. Scale bars equal $2 \mathrm{~mm}$.

maxilloturbinal starts at the level of the second upper incisor and ends on the level of the last upper premolar. However, it remains unclear if its anterior tip is still cartilaginous and therefore not visible in the $\mu \mathrm{CT}$ scan. Medially the maxillo- turbinal of the adult Tupaia shows several ridges that resemble epiturbinals not present in Ptilocercus (Figs. 4e, f, 7).

The nasoturbinal of the Ptilocercus fetus is a straight and in cross-section short lamella projecting from the dorsal sidewall of the nasal capsule (between tectum nasi and paries 
nasi) into the anterior nasal cavity above the maxilloturbinal. Its anterior extension is identical to that of the maxilloturbinal and caudally it fuses to the paries nasi very close to the maxilloturbinal (Figs. 2a, 5a). The bases of both turbinals remain widely separated.

By outgrowth the nasoturbinal pattern changes significantly in the adult stage. The ossified nasoturbinal is supported by a ridge of the nasal bone and starts somewhat behind the anterior tip of the maxilloturbinal as a short anterior process (Figs. 4a, b, 7a, c). However, it remains unclear if the anterior tip of the nasoturbinal is still cartilaginous as some soft tissue is visible in the $\mu \mathrm{CT}$ scan. Caudally the nasoturbinal ends above midway of the maxilloturbinal on its root (Figs. 4b, 7c). In the cross section the nasoturbinal is an almost straight lamella that is situated above the maxilloturbinal and never reaches the medial extension of the latter (Fig. 7a).

In the adult Tupaia the nasoturbinal is less developed than in Ptilocercus and resembles a quite slender lamella that appears to be displaced ventrally along its entire length. The anterior portion rises from the lateral border of the nasal, and posteriorly the nasoturbinal ends right above the base of the maxilloturbinal (Figs. 4c, d, 7b, d).

The lamina semicircularis (crista semicircularis) resembles a wall separating the border between the pars anterior and the pars lateralis. It develops as a posterior extension of the paries nasi (Zeller, 1987) and forms a sickle-shaped vertical but distinctly bent lamella in the fetal stage of Ptilocercus (Fig. 2a). The lamina semicircularis shows a prominent posteroventral processus uncinatus that supports the hiatus semilunaris. Lamina semicircularis and nasoturbinal are separated by a large gap (Fig. 2a).

The adult Ptilocercus shows a very similar pattern. However, the lamina semicircularis appears to have undergone a significant growth in height and length, and therefore it bulges out into the nasal cavity and forms the medial wall of the anterior confluent parts of the frontoturbinal recess and maxillary sinus (Figs. 4a, b, 7e, 8a). The lamina has a lateral epiturbinal-like outgrowth that is oriented dorsally. This structure becomes integrated into the swollen apical edges of the lamina's flanks above and below the hiatus semilunaris. The processus uncinatus of the ventral flank is still evident in the adult (Fig. 8a, c). Posteriorly, the dorsal flank becomes a horizontal lamina that shows an apical hollowed inflation and is continuous with the lamina cribrosa (Figs. 8c, 9a).

In the adult Tupaia several differences become evident. The lamina semicircularis is rostrally bifurcated, and thus the anterior tip of the recessus frontoturbinalis is separated from the maxillary sinus (Figs. 4c, d, 7f) (see below). The lamina shows a sharp central bent into the paranasal space (Fig. 8b). Tupaia also has a lateral and dorsally oriented epiturbinallike outgrowth, but it is separated from the lamina semicircularis by a long fissure; posteriorly it fuses to the dorsal flank above the hiatus semilunaris where it forms the hollow inflation of the dorsal flank's rim and continues into a scroll (Figs. 8b, d, 9b, 10b). The processus uncinatus is obviously much shorter in the fetal stages of Tupaia (Spatz, 1964; Zeller, 1983, 1987) compared to Ptilocercus, but in the adults it appears to be comparably developed (Figs. 4, 8d).

\subsection{Pars lateralis of nasal cavity}

In the chondrocranium the pars lateralis (pars intermedia) of the ethmoidal region is subdivided into two compartments by the lamina horizontalis (pars obtecta of paries conchalis); the latter gives rise to most of the olfactory turbinals (Voit, 1909; Reinbach, 1952a, b). The primary sidewall of the pars lateralis but also of the pars posterior is called the pars libera. The dorsal compartment is the recessus lateralis superior, which includes the posterior recessus frontoturbinalis that houses the frontoturbinals and the anterior recessus frontalis. Rostrally it is confluent with the ventral space, the so-called recessus lateralis inferior (recessus maxillaris). This space is the precursor of the sinus maxillaris in the adult; it houses two large nasal glands: the serous glandula nasi lateralis and the mucous glandula sinus maxillaris (Broman, 1921; Ruf, 2004). Medially the pars lateralis is limited by the lamina semicircularis and the first ethmoturbinal. Both recessus are confluent with the paraseptal space via the hiatus semilunaris. The Scandentia under study resemble this general therian pattern (Figs. 2, 4a-d).

The lamina horizontalis of the Ptilocercus fetus is rostrally prolonged by a septum frontomaxillare. Comparing the fetal stages of Ptilocercus and Tupaia belangeri it is evident that the former has a smaller recessus lateralis superior than the latter. In the adult Ptilocercus the pars obtecta shows several specific small ventral ridges (Fig. 9a).

Ptilocercus has two frontoturbinals which are already present in the fetal stage (Figs. 2a, 6a). Frontoturbinal 1 is a distinct lamella that starts on the anterior projection of the lamina horizontalis and curves caudodorsally along the paries nasi to the roof of the nasal cavity. It fuses to the lamina cribrosa at its posterior end. The second frontoturbinal is shorter and less developed in the fetus. Frontoturbinal 2 is a low ridge that starts more posteriorly on the paries nasi and runs more or less parallel but below frontoturbinal 1. In the adult Ptilocercus both frontoturbinals have significantly evolved and their rostral attachments have changed (Fig. 4a, b). Frontoturbinal 1 has two anterior processus: a longer medial one that starts anterior of the hiatus semilunaris between lamina semicircularis and ethmoturbinal I and a shorter lateral one that projects laterally of the lamina semicircularis into the confluent space of the recessus frontalis and recessus maxillaris (Figs. 4b, 8a, b). Both processus unite in the hiatus semilunaris and become the double scroll that is attached to the lamina horizontalis for a very short way. Frontoturbinal 2 starts with an anterior process that is inserted into the ventral scroll of frontoturbinal 1 (Fig. 8b). It lies ventrally of the latter and attaches to the lamina horizontalis forming the typical double scroll. Both frontoturbinals are large double- 

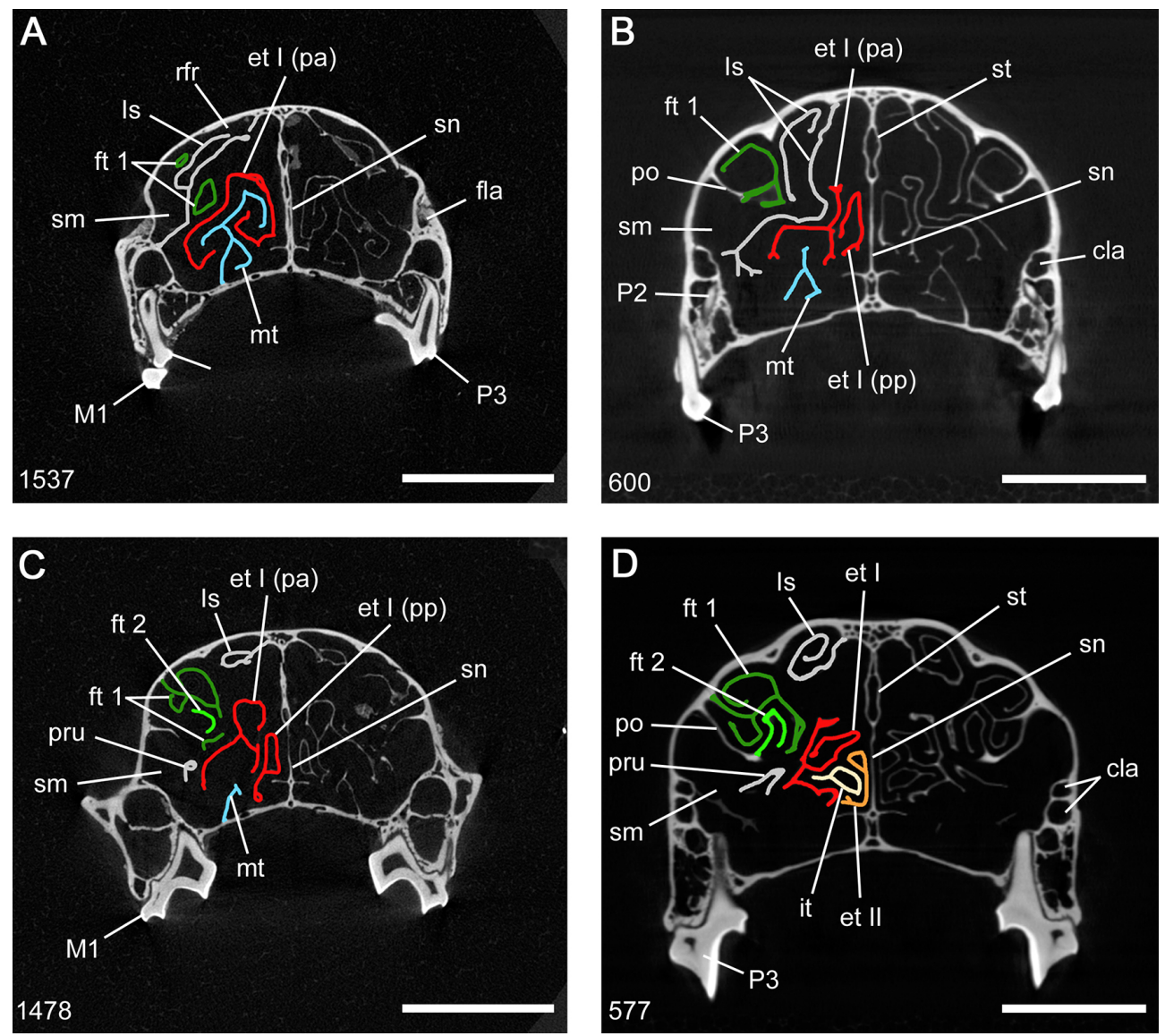

Figure 8. $\mu \mathrm{CT}$ cross-section images of the pars lateralis and posterior of the adult rostrum from anterior to posterior of (a, c) Ptilocercus lowii (ZMB 3992) and (b, d) Tupaia sp. (collection W. Maier). Numbers in figures refer to number of original $\mu$ CT slices. Abbreviations: cla, canaliculus lacrimalis; et I, II, ethmoturbinal I, II; fla, foramen lacrimale; ft 1, 2, frontoturbinal 1, 2; it, interturbinal; ls, lamina semicircularis; M1, upper molar 1; mt, maxilloturbinal; P2, 3, upper premolar 2, 3; pa, pars anterior; po, pars obtecta (paries conchalis); pp, pars posterior; pru, processus uncinatus; rfr, recessus frontalis; sm, sinus maxillaris; sn, septum nasi; st, septoturbinal. Scale bars equal 2 mm.

scrolled structures, mushroom-like in cross section, except for their anterior portions and are posteriorly fused to the lamina cribrosa (Figs. 9a, 10a, 11a, 12a).

The adult Tupaia also has two frontoturbinals that generally resemble the same pattern as in Ptilocercus (Figs. 4c, d, $8 b, d, 9 b, 10 b, 11 b, 12 b)$. However, their shape differs significantly. Frontoturbinal 1 of Tupaia has only one anterior process lateral to the lamina semicircularis; by attaching to the lamina horizontalis it becomes also a double scroll, but the two laminae are much more coiled and therefore obviously proportionally larger than in Ptilocercus (Figs. 4d, 8b, d, 9b, 10b). Frontoturbinal 2 also starts with an anterior process that is embraced by the ventral and a short third lamella of frontoturbinal 1 (Fig. 8d). Posteriorly this third lamella becomes the actual ventral scroll whereas the former ventral lamella becomes reduced. Frontoturbinal 2 of Tupaia is a single scroll that is curled medially (Figs. 8b, 9b, 10b, 11b, $12 b)$.
The recessus lateralis inferior of Ptilocercus is a flat ovoid space that is connected to the paraseptal medially. The sinus maxillaris of the adult stage has expanded significantly. It starts together with the recessus lateralis superior above the second upper molar. The posterior end of the sinus continuous into the paraseptal space and the ductus nasopharyngeus. Thus it is not distinct in the cleaned skull because no glands are present that can be used as landmarks. The sinus maxillaris is still ovoid in shape but changed to a more vertical orientation (Figs. 8a, c, 9a, 10a, 11a, 12a).

In the adult Tupaia the sinus maxillaris is a large cavity whose anterior tip is separated from the recessus frontalis by a short bony plate that is most probably an ossified septum frontomaxillare (Fig. 7f). The sinus starts on the level of the first upper premolar and ends - contrary to the pattern in Ptilocercus - as a closed space above the second upper molar ventromedial of the orbit. Medially the sinus maxillaris is partly confluent with the paraseptal space and the duc- 

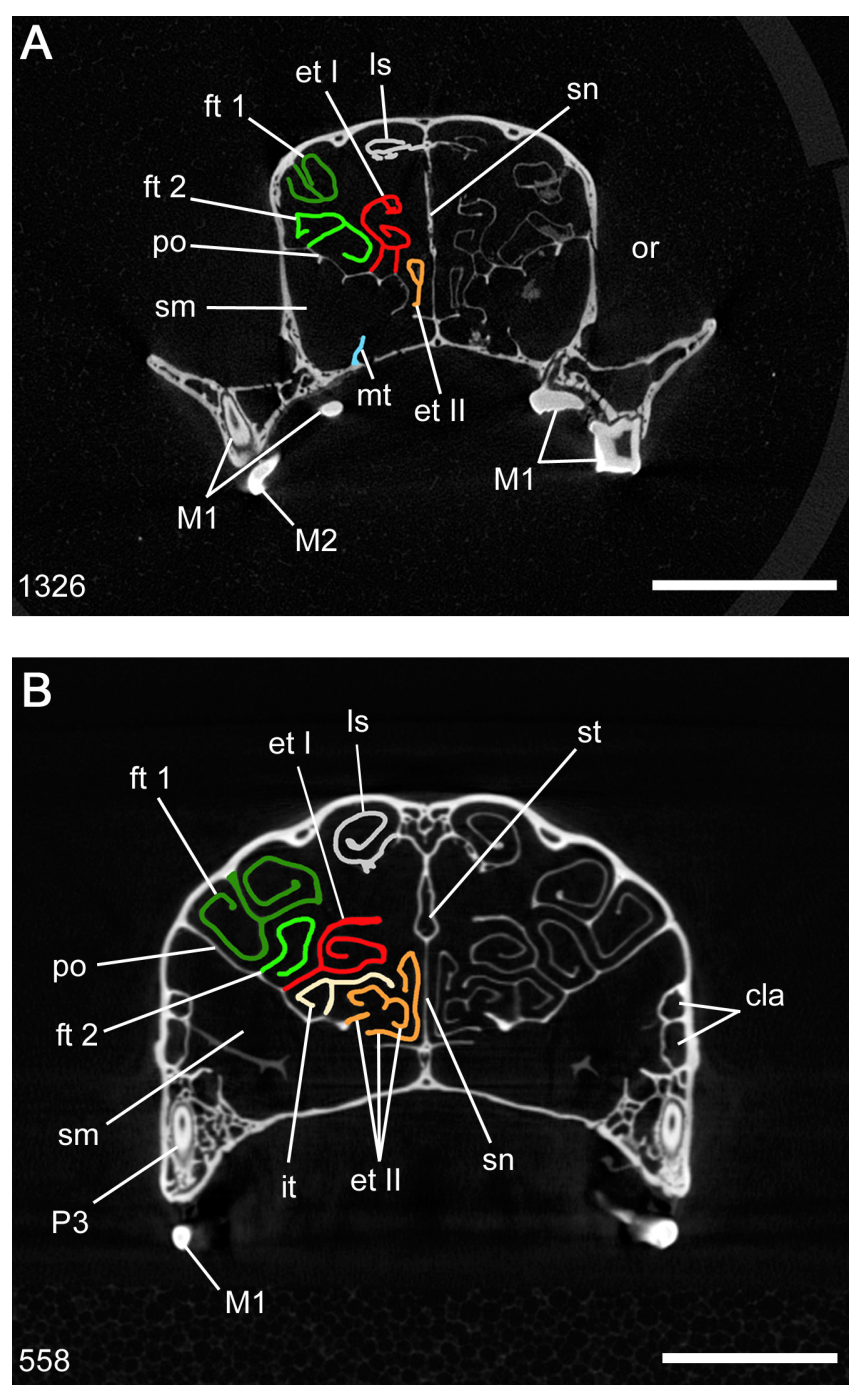

Figure 9. $\mu \mathrm{CT}$ cross-section images of the pars lateralis and posterior of the adult rostrum from anterior to posterior of (a) Ptilocercus lowii (ZMB 3992) and (b) Tupaia sp. (collection W. Maier). Numbers in figures refer to number of original $\mu \mathrm{CT}$ slices. Abbreviations: cla, canaliculus lacrimalis; et I, II, ethmoturbinal I, II; ft 1, 2, frontoturbinal 1, 2; it, interturbinal; 1s, lamina semicircularis; M1, 2, upper molar 1, 2; mt, maxilloturbinal; or, orbit; P3, upper premolar 3; po, pars obtecta (paries conchalis); sm, sinus maxillaris; sn, septum nasi; st, septoturbinal. Scale bars equal $2 \mathrm{~mm}$.

tus nasopharyngeus. The sinus is mostly rectangular in shape (Figs. 8b, d, 9b, 10b, 11b).

Further expansions of the nasal cavity into surrounding bones are not present in any of the investigated Scandentia species, which possess neither frontal sinus nor a distinct sphenoid sinus (as already observed by Negus, 1958, and Wible, 2011). However, in the adult stage of Tupaia the spaces between the lamina semicircularis, the frontoturbinals, and the brain cavity itself bulge out distinctly as clearly seen in cross section (Figs. 8d, 9b, 10b). Thus based
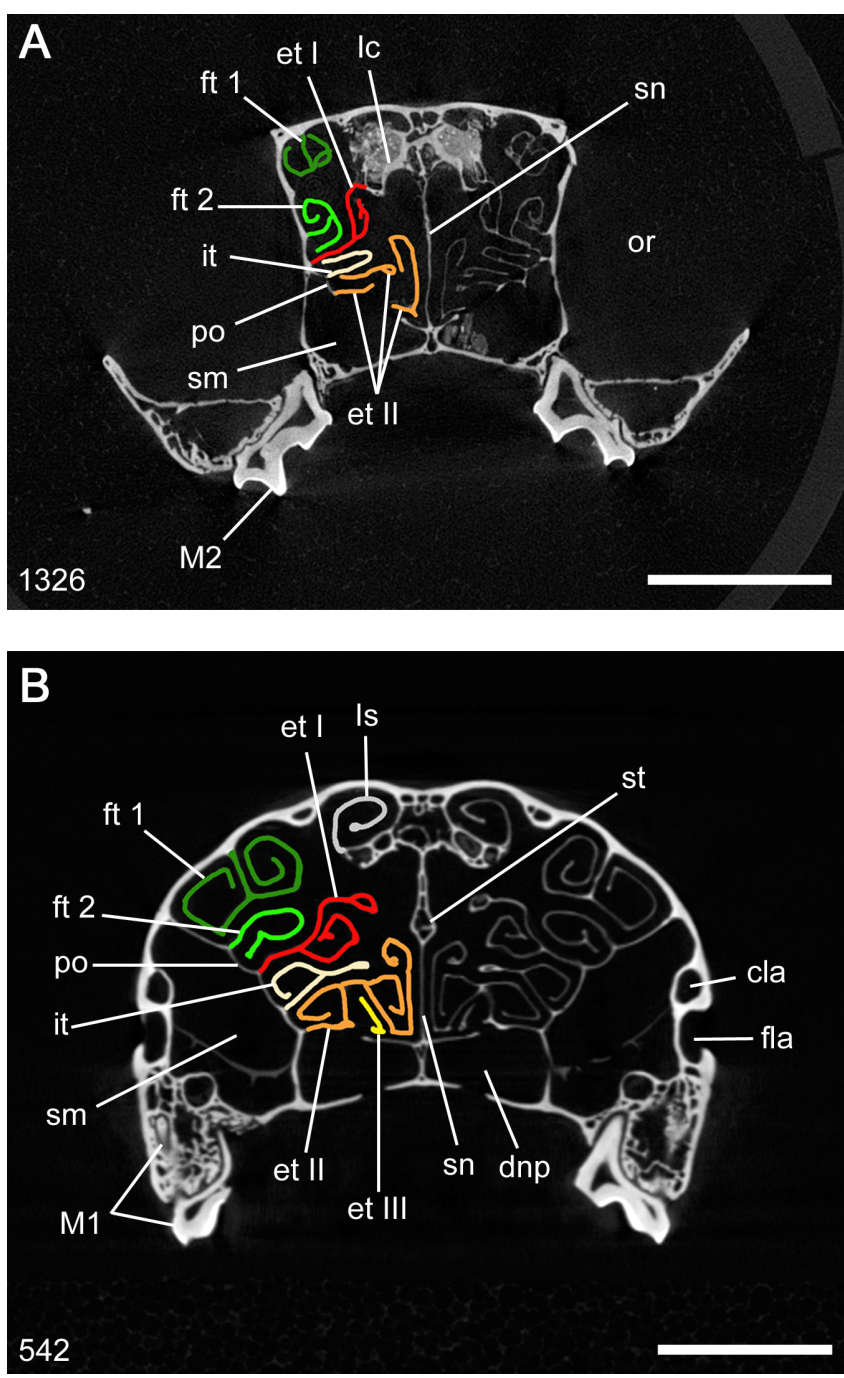

Figure 10. $\mu \mathrm{CT}$ cross-section images of the pars lateralis and posterior of the adult rostrum from anterior to posterior of (a) Ptilocercus lowii (ZMB 3992) and (b) Tupaia sp. (collection W. Maier). Numbers in figures refer to number of original $\mu \mathrm{CT}$ slices. Abbreviations: cla, canaliculus lacrimalis; dnp, ductus nasopharyngeus; et I, II, III, ethmoturbinal I, II, III; fla, foramen lacrimale; ft 1, 2, frontoturbinal 1, 2; it, interturbinal; lc, lamina cribrosa; 1s, lamina semicircularis; M1, 2, upper molar 1, 2; or, orbit; po, pars obtecta (paries conchalis); sm, sinus maxillaris; sn, septum nasi; st, septoturbinal. Scale bars equal $2 \mathrm{~mm}$.

on external anatomy the existence of extensive frontal sinus is indicated, which is apparently not the case. Perinatal ontogenetic stages of Tupaia do not clearly show this feature yet.

\subsection{Pars posterior of nasal cavity}

The pars posterior comprises the recessus ethmoturbinalis that houses the majority of the olfactory turbinals. Ptilocercus and Tupaia both have three ethmoturbinals and one inter- 
turbinal (Figs. 2, 4). Though more or less identical in rostrocaudal extension the pars posterior is significantly wider in the Ptilocercus fetus than in the neonate of Tupaia glis. The posterior portion of the nasal capsule of the fetal Ptilocercus reaches the radix anterior of the pila praeoptica (Fig. 1a). Thus a foramen supraseptale is separated from the fissura orbitonasalis. In contrast the fetal stage of Tupaia does not show any fragmentation of the fissura.

In the fetal Ptilocercus ethmoturbinal I is by far the largest olfactory turbinal and already has two anterior portions: pars anterior and pars posterior (Figs. 2a, 5b, 6a). The pars anterior projects into the pars anterior of the nasal cavity with a processus anterior that is triangular in cross section and pointed. In comparison the processus anterior of Ptilocercus is proportionally longer than that of Tupaia glis (Fig. 2). The pars anterior of ethmoturbinal I is separated from the pars posterior by a deep medial cavity (Fig. 6a). Both parts of the first ethmoturbinal are simple lamellae in the fetal stage. The ethmoturbinal I is connected to the pars obtecta of the paries conchalis and ends on the lamina cribrosa (Fig. 6b).

In the adult Ptilocercus the first ethmoturbinal has become a complex structure. Both parts of ethmoturbinal I are extremely different in size. More than half of the turbinal is represented by the processus anterior of the pars anterior and the pars posterior is extremely short (Fig. 4a). The processus anterior projects far into the pars anterior of the nasal cavity. In contrast to the fetus the process is a lamella from the beginning and becomes a dome-shaped structure above the nasoturbinal and maxilloturbinal (Fig. 7a, c, e). Further posteriorly the processus anterior completely embraces the dorsal lamella of the maxilloturbinal (Figs. 7e, 8a). On a level with the anterior rim of the hiatus semilunaris the dorsal part of the processus anterior develops a sinus. The ventral portion is continuous with the lamina horizontalis whereas the dorsal sinus of the processus anterior becomes the medially curled lamella of the pars anterior. The pars posterior starts with an anterior process between septum nasi and pars anterior of ethmoturbinal I (Fig. 8c). Anteriorly it forms a vertical sinus that develops a ventral lamella. The latter becomes incorporated into the lamina horizontalis. The dorsal hollow portion of the pars posterior transforms into a laterally curled lamella that is nested in the scroll of the pars anterior (Fig. 9a). Anteriorly the pars posterior is fused to the lamina horizontalis but then originates from the proximal pars anterior (Figs. 9a, 10a, 11a, 12a).

Ethmoturbinal I of Tupaia shows some different proportions. As already observed in fetal stages the pars posterior is proportionally larger than in Ptilocercus (Figs. 4c, 7b, d, f, $8 b, d, 9 b, 10 b, 11 b, 12 b)$.

The ethmoturbinal II is a sagittal lamella in the fetus of Ptilocercus (Fig. 2a). Rostrally it originates from the pars obtecta but runs caudolaterally onto the pars libera. Its posterior end fuses to the lamina cribrosa. Laterally the ethmoturbinal II shows a second lamella.
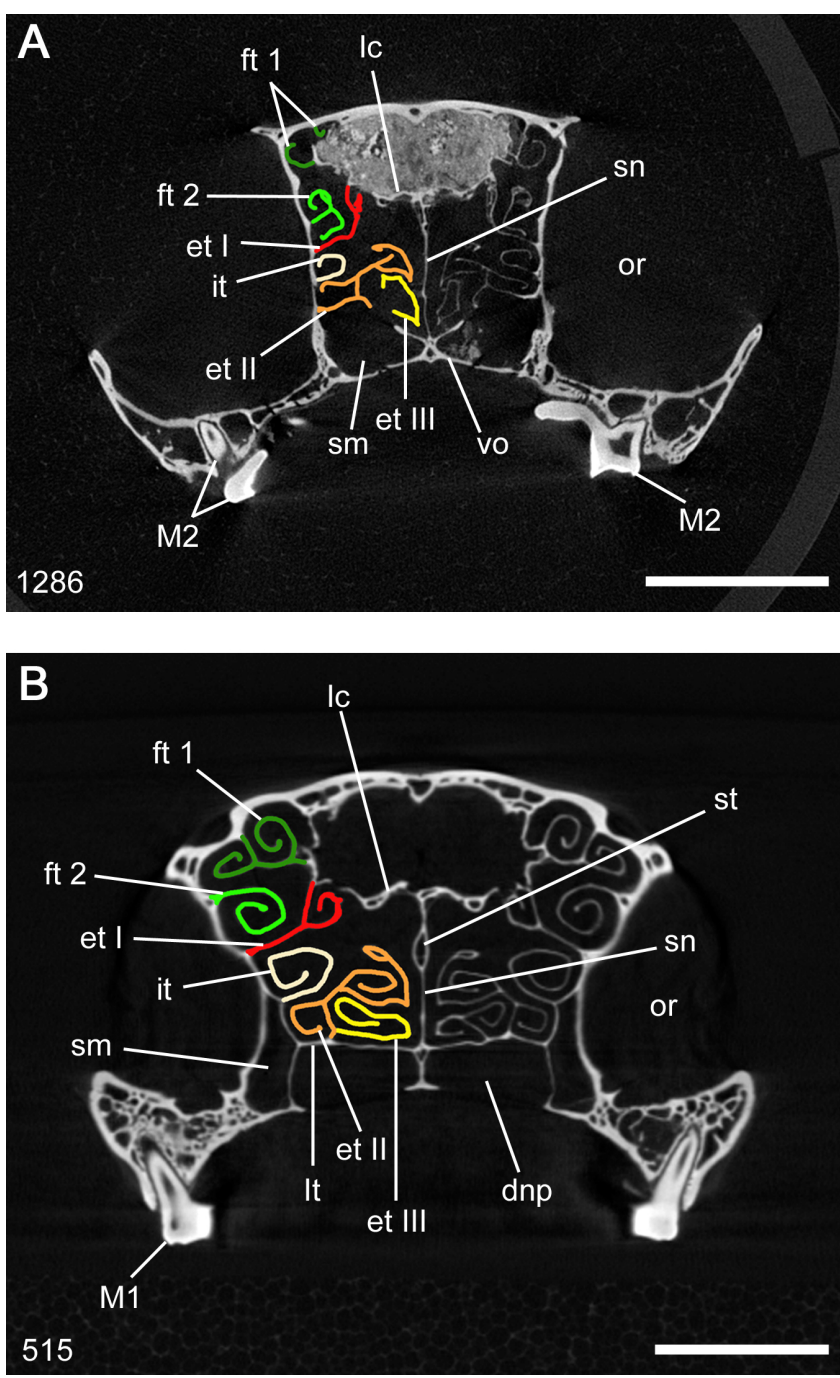

Figure 11. $\mu \mathrm{CT}$ cross-section images of the pars lateralis and posterior of the adult rostrum from anterior to posterior of (a) Ptilocercus lowii (ZMB 3992) and (b) Tupaia sp. (collection W. Maier). Numbers in figures refer to number of original $\mu C T$ slices. Abbreviations: dnp, ductus nasopharyngeus; et I, II, III, ethmoturbinal I, II, III; ft 1, 2, frontoturbinal 1, 2; it, interturbinal; lc, lamina cribrosa; M1, 2, upper molar 1, 2; or, orbit; sm, sinus maxillaris; sn, septum nasi; st, septoturbinal; vo, vomer. Scale bars equal $2 \mathrm{~mm}$.

In the adult stage of Ptilocercus the second ethmoturbinal has an anterior process that projects anteriorly between interturbinal and septum nasi. The tip of the processus anterior is a vertical lamella that increases posteriorly and develops a dorsal cavity (Figs. 4a, 9a). This cavity opens laterally; thus the anterior process of ethmoturbinal II becomes L-shaped. Further posterior the dorsal part of the process curls laterally and fuses to a second processus anterior. This second process is situated laterally from the first one and its anterior tip projects into the hollowed base of the interturbinal (Fig. 10a). The lateral anterior process is a horizontal lamella that develops a medial short cavity that opens ventrally just in front of 
the fusion of both processus. The ethmoturbinal II becomes a complicated and multi-branched lamella (Figs. 11a, 12a). It appears to fuse with the posterior end of the lamina horizontalis. However, there is a vague transition from the lamina horizontalis to the base of ethmoturbinal III from which ethmoturbinal II thus emerges before it runs on the sidewall of the nasal cavity. From here on ethmoturbinal II is an oblique lamella that connects to the lamina cribrosa and that has a lateral double scroll, further posterior a single-scroll portion (Fig. 13a). Ethmoturbinal II of Tupaia resembles the pattern observed in Ptilocercus though it is proportionally larger in the former (Figs. 2b, 4c, 8d, 9b, 10b, 11b, 12b, 13b).

In the Ptilocercus fetus the ethmoturbinal III is a sickleshaped simple lamella that originates from the pars libera of the paries conchalis. Caudally it is continuous with the lamina cribrosa (Fig. 2). In the adult Ptilocercus the third ethmoturbinal has a triangular hollow processus anterior that projects ventrally of the second ethmoturbinal (Figs. 4c, 11a). Running posteriorly the cavity opens laterally and in contrast to the fetal pattern the ventral part fuses to the presumably posterior end of the lamina horizontalis and the base of ethmoturbinal II, respectively, and thus forms a large horizontal plate that forms a scroll dorsally. More posteriorly the base of ethmoturbinal III moves to the side wall of the nasal cavity (Figs. 12a, 13a, 14a). Here the scroll of ethmoturbinal III becomes complicated and the posterior part of the turbinal is tripartite forming a mushroom-shaped double scroll in dorsal view. After fusion to the lamina cribrosa the lateral part of the scroll becomes isolated as a posterior process. Right before it ends the same happens to the medial part of ethmoturbinal III (Fig. 14a). Thus the remaining ethmoturbinal forms a septum that encloses a quadrangular cavity. The medial posterior process ends with a cavity in the cupula nasi posterior (Fig. 15a).

In general the third ethmoturbinal of Tupaia shows the same morphology though some differences occur in the adult (Figs. 2b, 4c, 10b, 11b, 12b, 13b, 14b, 15b). Those affect the proportions and the anterior process of ethmoturbinal III projecting into a proximal cavity of ethmoturbinal II.

Between the first and second ethmoturbinal the fetus of Ptilocercus already shows an interturbinal (Fig. 2a). It forms a distinct sagittal cartilaginous ridge that runs from the pars obtecta to the lamina cribrosa. Medially the interturbinal does not reach the same extension as the ethmoturbinals, a pattern that defines interturbinals (see Paulli, 1900a).

In the adult Ptilocercus the interturbinal starts with an anterior process that projects into a basal cavity at the base of the first turbinal. The processus anterior itself forms more or less triangular cavity that opens ventrally above the lamina horizontalis. In cross section the interturbinal is a horizontal lamella that is curved dorsally in the middle. The interturbinal fuses to a hollowed outgrowth of the lamina horizontalis that represents the base or root of the interturbinal. However, only the lateral portion becomes the interturbinal main body whereas the medial part is again integrated into
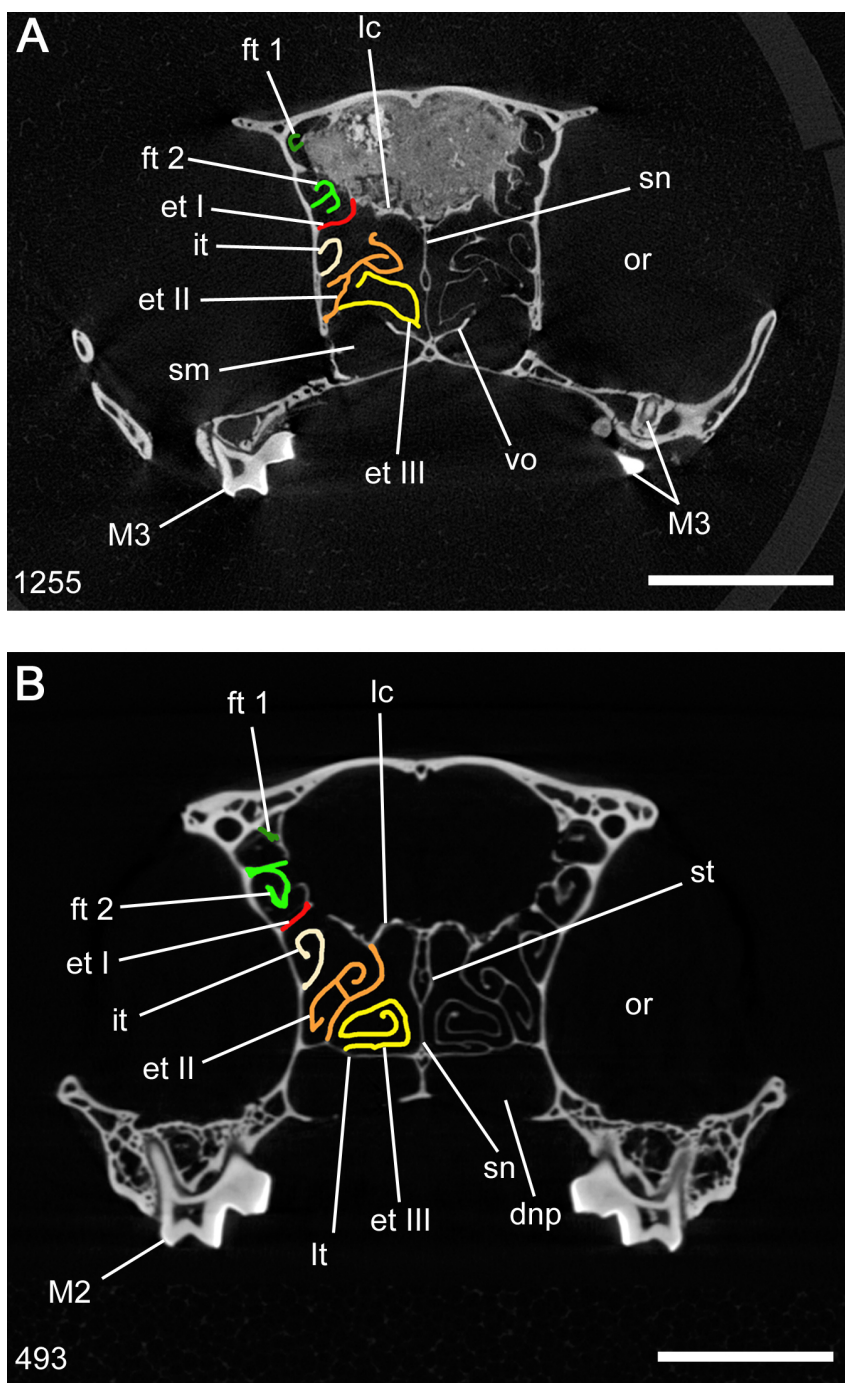

Figure 12. $\mu \mathrm{CT}$ cross-section images of the pars posterior of the adult rostrum from anterior to posterior of (a) Ptilocercus lowii (ZMB 3992) and (b) Tupaia sp. (collection W. Maier). Numbers in figures refer to number of original $\mu \mathrm{CT}$ slices. Abbreviations: dnp, ductus nasopharyngeus; et I, II, III, ethmoturbinal I, II, III; ft 1, 2, frontoturbinal 1, 2; it, interturbinal; lc, lamina cribrosa; M2, 3, upper molar 2, 3; or, orbit; sm, sinus maxillaris; sn, septum nasi; st, septoturbinal; vo, vomer. Scale bars equal $2 \mathrm{~mm}$.

the lamina horizontalis (Fig. 10a). The interturbinal is a simple scroll that is curled dorsally (Figs. 11a, 12a).

The interturbinal of the adult Tupaia is comparable to Ptilocercus except for its anterior portion. Between the processus anterior and the single scroll for a short distance, the interturbinal of Tupaia is a double scroll, i.e. mushroomshaped in cross section (Figs. 8d, 9b, 10b, 11b, 12b).

The cupula nasi posterior forms the posterior end of the nasal cavity (Figs. 1a, 2a). In the fetus of Ptilocercus it is still completely cartilaginous and its radius is significantly larger than in the neonate Tupaia (Zeller, 1983, 1987). 

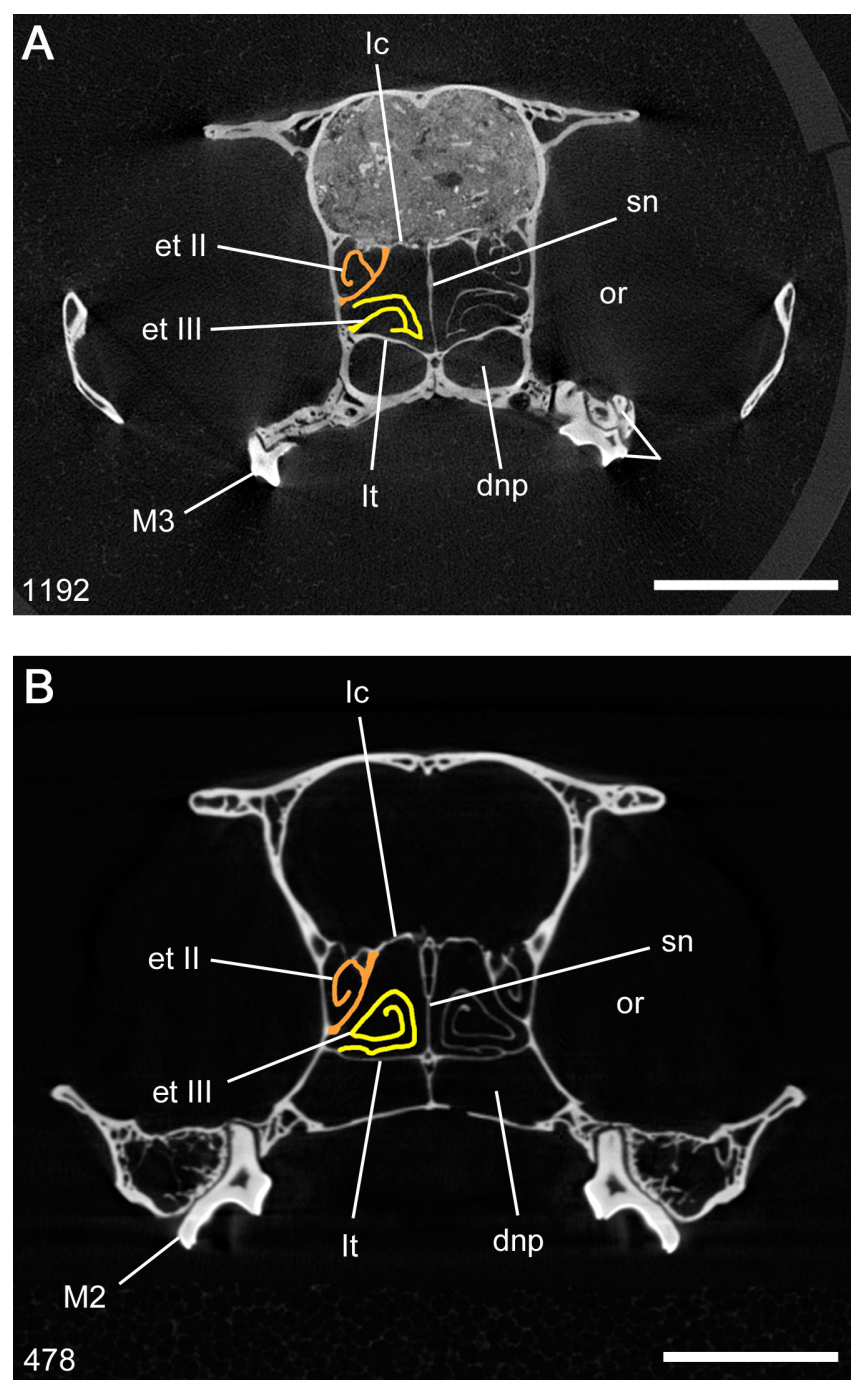

Figure 13. $\mu \mathrm{CT}$ cross-section images of the pars posterior of the adult rostrum from anterior to posterior of (a) Ptilocercus lowii (ZMB 3992) and (b) Tupaia sp. (collection W. Maier). Numbers in figures refer to number of original $\mu \mathrm{CT}$ slices. Abbreviations: dnp, ductus nasopharyngeus; et II, III, ethmoturbinal II, III; lc, lamina cribrosa; lt, lamina terminalis; M2, 3, upper molar 2, 3; or, orbit; sn, septum nasi. Scale bars equal $2 \mathrm{~mm}$.

In the adult stage the cupula nasi posterior is completely ossified and integrated in the surrounding bones of the orbit. In Ptilocercus the cupula nasi posterior is rectangular in cross section whereas in Tupaia it is laterally compressed (Fig. 15a, b).

\subsection{Solum nasi}

The solum nasi (nasal floor) consists of several elements in the chondrocranium: lamina transversalis anterior, cartilago paraseptalis (houses the vomeronasal organ), and lamina transversalis posterior (Fig. 2). Here we only refer to the lamina transversalis posterior, because the lamina transver-
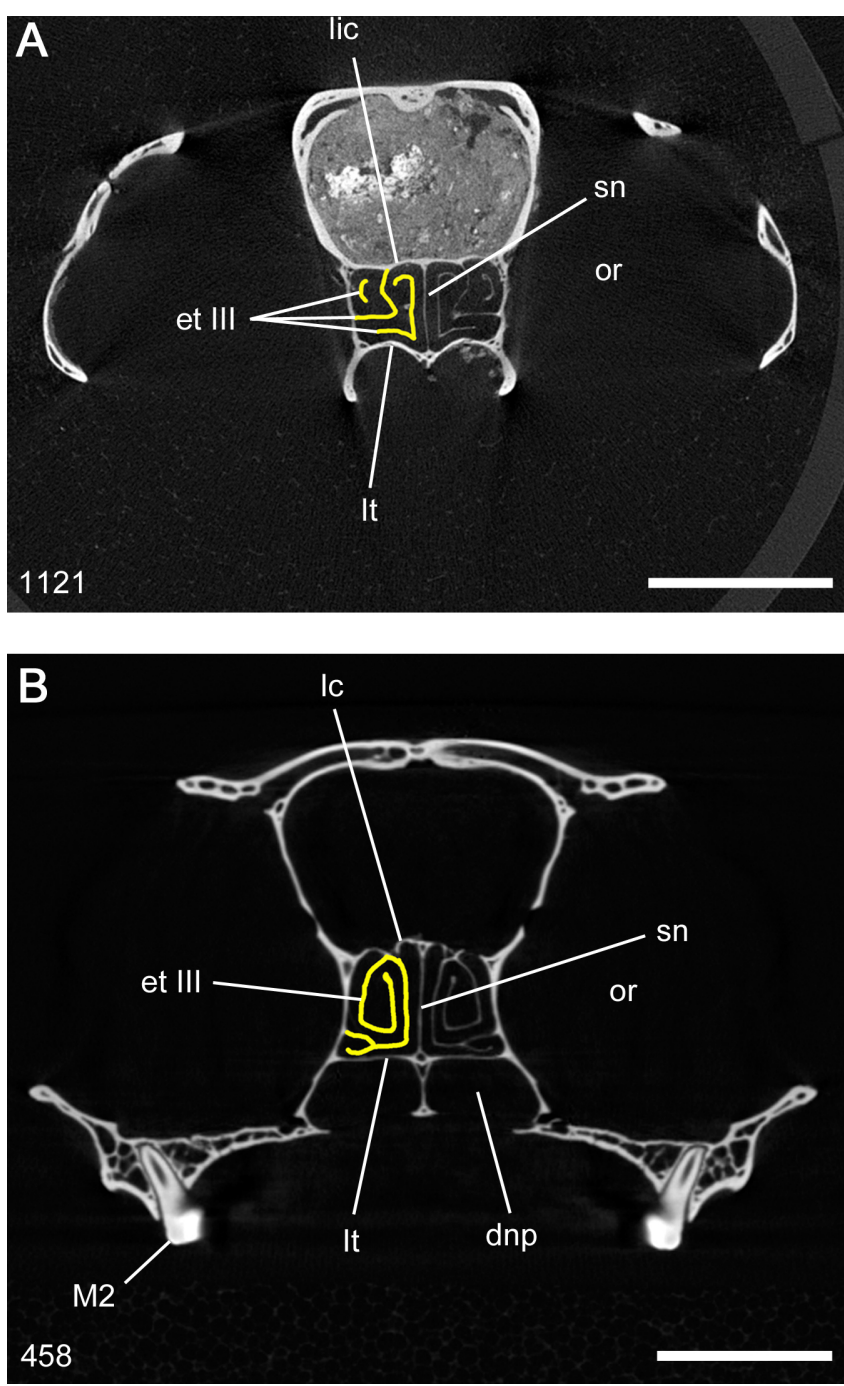

Figure 14. $\mu \mathrm{CT}$ cross-section images of the pars posterior of the adult rostrum and orbit from anterior to posterior of (a) Ptilocercus lowii (ZMB 3992) and (b) Tupaia sp. (collection W. Maier). Numbers in figures refer to number of original $\mu \mathrm{CT}$ slices. Abbreviations: dnp, ductus nasopharyngeus; et III, ethmoturbinal III; lc, lamina cribrosa; lic, lamina infracribrosa; lt, lamina terminalis; M2, upper molar 2; or, orbit; sn, septum nasi. Scale bars equal $2 \mathrm{~mm}$.

salis anterior is still cartilaginous in the adult and therefore not visible in the $\mu \mathrm{CT}$ scan, and the cartilago paraseptalis is generally replaced by the medial palatine process of the premaxilla and maxilla (see Ruf, 2004).

The lamina transversalis posterior is a horizontal cartilaginous plate in the fetal stage of Ptilocercus and separates the posterior end of the nasal cavity from the ductus nasopharyngeus. From the septum nasi the entire lamina transversalis posterior is separated by a distinct fissure. The vomer lies beneath the septum nasi and the lamina transversalis posterior and fuses partly with the latter. Laterally the lamina is con- 

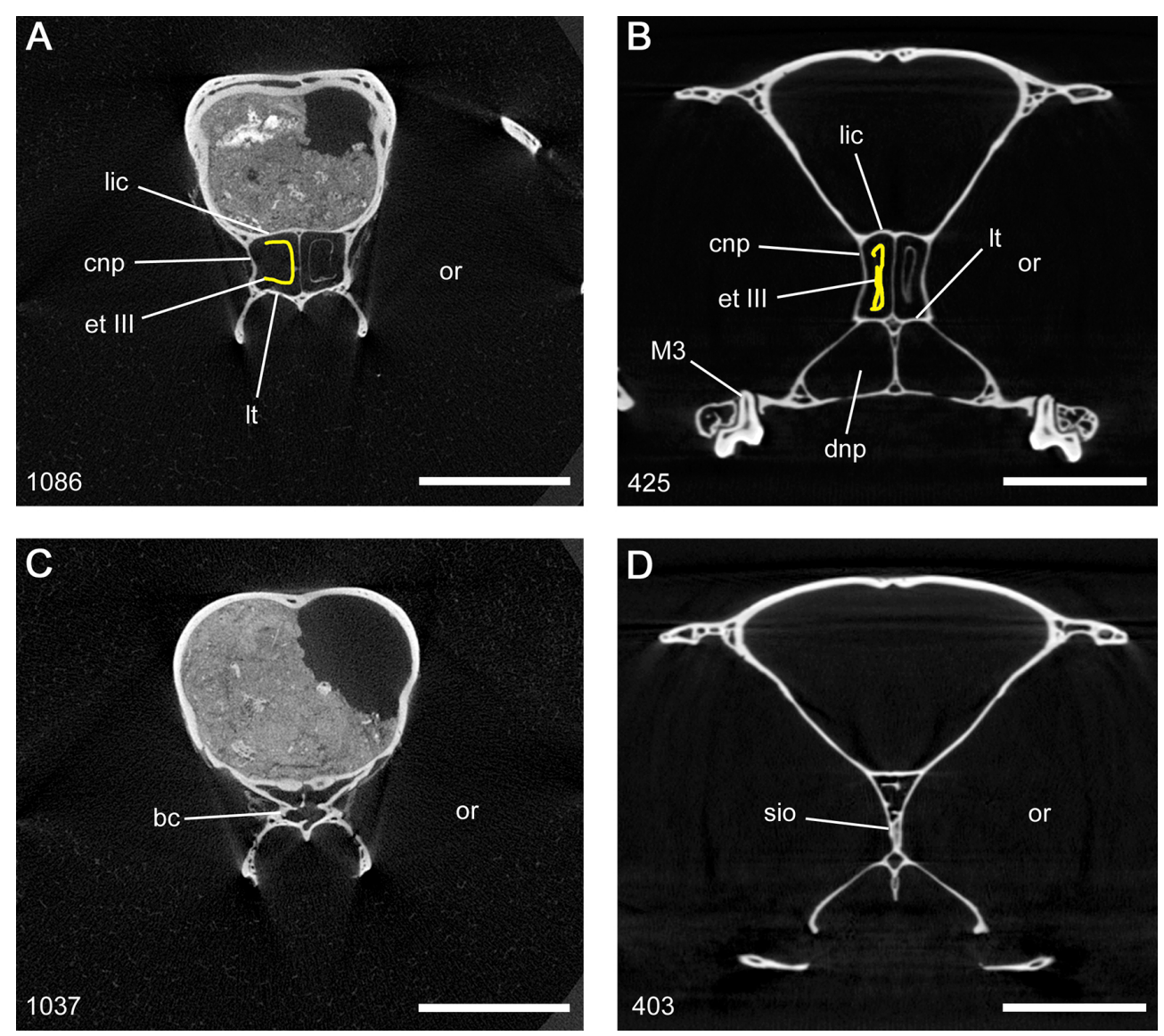

Figure 15. $\mu \mathrm{CT}$ cross-section images of the cupula nasi posterior of the adult rostrum and the anterior orbitotemporal region from anterior to posterior of (a, c) Ptilocercus lowii (ZMB 3992) and (b, d) Tupaia sp. (collection W. Maier). Numbers in figures refer to number of original $\mu \mathrm{CT}$ slices. Abbreviations: bc, basicranium; cnp, cupula nasi posterior; dnp, ductus nasopharyngeus; et III, ethmoturbinal III; lic, lamina infracribrosa; lt, lamina terminalis; M3, upper molar 3; or, orbit; sio, septum interorbitale. Scale bars equal $2 \mathrm{~mm}$.

tinuous with the paries nasi, posteriorly with the cupula nasi posterior.

In adult stages the lamina transversalis posterior is synossified with the vomer. As both elements are not distinguishable the entire structure is called lamina terminalis. In Ptilocercus the lamina terminalis is V-shaped. Anteriorly it is continuous with the vomer and its alae. The posterior half of the lamina terminalis bulges out into the ethmoturbinal recess (Figs. 13a, 14a, 15a). In contrast the lamina terminalis of the adult Tupaia is positioned horizontally (Figs. 11b, 12b, 13b, $14 \mathrm{~b}, 15 \mathrm{~b})$.

\section{Discussion}

Ptilocercidae and Tupaiidae show many similar but also significantly different cranial features which are associated with size and proportion of the ethmoidal region and orbit orientation, and therefore correlated to the behavioural biology of the investigated species.
Beside vision, olfaction is a major sense in nocturnal and arboreal mammals especially for social and sexual communication (Epple et al., 1993). Ptilocercus is an arboreal and nocturnal hunter; thus stereoscopic vision is highly important while foraging on insects, which explains the larger, more anteriorly positioned and frontally oriented orbits compared to Tupaia. In contrast Tupaia species are mainly diurnal, most of which forage on the ground and in bushes and thus stereoscopic vision might be less important (Hofer, 1957; Cartmill, 1972; Sargis, 2001). Though Scandentia have relatively large eyes the posterior ethmoidal region is not reduced (see Smith et al., 2014b). Our new findings on the investigated Scandentia support earlier observations on Tupaia that the nasal cavity of Scandentia is well-developed and clearly indicates macrosmatic sense, the ability of high olfactory performance (Spatz, 1964; Zeller, 1987; Smith et al., 2014b). Macrosmatic ability is a plesiomorphic mammalian character (see Maier and Ruf, 2014), and many of the here described characters and ontogenetic transformations are correlated with this feature and represent plesiomorphic states for the clade Scan- 
dentia (Zeller, 1986b, 1987; Maier and Ruf, 2014; Ruf, 2004, 2014).

Throughout ontogeny the ethmoidal region is proportionally longer in Ptilocercus than in Tupaia, though a general expansion occurs in postnatal growth of both taxa. The crucial differences in proportion of the posterior ethmoidal region of the investigated Scandentia, such as shape of lamina cribrosa, shape of lamina horizontalis, crista galli and spina mesethmoidalis in Tupaia, are caused by size and orientation of the orbits and interaction with associated structures of the olfactory nervous system. The nasal capsule of Ptilocercus is relatively longer than in Tupaia and shows different proportions. The pars posterior of the Ptilocercus fetal nasal cavity is slightly longer than the pars anterior whereas in $\mathrm{Tu}$ paia both compartments are similar in length. Much more evident are proportional differences concerning the width of the nasal cavities. Ptilocercus has a wider pars posterior than Tupaia. The lamina cribrosa shows a complementary pattern: the area that leads the fila olfactoria of the ethmoidal recess is wider in Ptilocercus than in Tupaia, thus indicating a greater olfactory importance of the ethmoturbinals in Ptilocercus.

A macrosmatic ethmoidal region is reduced or even lost in certain mammalian clades, e.g. in cetaceans (Klima, 1999; Berta et al., 2014). Primates, another striking example, show the evolutionary tendency to highly reduce number and complexity of turbinals due to adaptations to an arboreal life along with stereoscopic vision. Thus, not only is olfaction less important in haplorhine primates but also the enlarged eyes and rostrally oriented orbits are conflicting with the posterior nasal capsule in terms of the demand for space (Maier, 1983; Maier and Ruf, 2014). However, Scandentia have an elaborated ethmoidal region with well-developed olfactory turbinals which is obviously not in spatial conflict with the enlarged eyes (Smith et al., 2014b). As skull size, chewing apparatus, basicranial kyphosis, and proportion of the brain cavity are comparable in Ptilocercus and Tupaia, these factors obviously do not influence the morphology of the anterior basicranium, i.e. the existence of a septum interorbitale in the latter (Haines, 1950; Spatz, 1964, 1970; Starck, 1979; see discussion below). Thus, the most striking features to be discussed are the internal organization of the nasal in terms of turbinals as well as the pattern of the posterior tip of the ethmoidal region, the occurrence of a septum interorbitale.

\subsection{Turbinal pattern}

The nasal capsule of mammals shows a quite uniform Bauplan in early ontogeny though it becomes modified with often highly complex ossified structures and partly resorbed in later stages (Maier and Ruf, 2014). In general the ethmoidal region of Ptilocercus resembles the pattern observed in $\mathrm{Tu}$ paia. Comparing the proportions of the ossified turbinals in the adult skull of Ptilocercus and Tupaia it is evident that in the former the fronto- and ethmoturbinals as well as the interturbinal are proportionally smaller (shorter) than in the latter.
The demand for space of the orbits in Ptilocercus restricts the lateral parts of the nasal cavity that results in a narrower ethmoidal region that elongates posteriorly as far as the anterior border of the pila praeoptica in the fetus. Furthermore, the frontoturbinals of Ptilocercus are less developed than in Tupaia due to the fact that the pars lateralis and therefore the frontoturbinal recess are larger in the latter. This shift in proportions leads to the incorporation of the skull base between cupula nasi posterior and pila praeoptica in the nasal capsule, whereas in Tupaia the equivalent structure forms the septum interorbitale. Thus, the observed differences in the proportions of the pars posterior might serve as compensation.

The observed number of olfactory turbinals (two frontoturbinals, three ethmoturbinals, one interturbinal between ethmoturbinal I and II) in Ptilocercus does not support the data provided by Le Gros Clark (1926) and Wible (2011). While the former describes two ectoturbinals in the pars lateralis that correspond to the two frontoturbinals, Wible (2011) reports three ectoturbinals. We can clearly demonstrate that this interpretation is not correct. Wible's three lateral ectoturbinals obviously comprise the lamina semicircularis and the two frontoturbinals. Both authors describe four ethmoturbinals in the pars posterior. Our investigation clearly demonstrates that Ptilocercus has only three ethmoturbinals. Obviously the interturbinal has been erroneously included into the ethmoturbinals by Le Gros Clark (1926) and Wible (2011). These results clearly demonstrate the advantage of $\mu \mathrm{CT}$-based investigations of adult nasal cavities to enhance the three-dimensional understanding of bony structures. Furthermore as already mentioned above the consistent use of an adequate terminology is demanded in nasal anatomy.

All investigated species of Tupaia have the same number of turbinals as Ptilocercus. Thus we can confidently conclude that two frontoturbinals, and three ethmoturbinals plus one interturbinal represent the morphotype of Scandentia. This pattern is also observed in many small-sized mammals but especially in members of the Euarchontoglires like many leporids, rodents, and Dermoptera (Paulli, 1900c; Voit, 1909; Frick and Heckmann, 1955; Zeller, 1987; Ruf, 2004, 2014; Maier and Ruf, 2014). Therefore the ethmoidal pattern of Scandentia may represent the plesiomorphic ground plan pattern (sensu Hennig, 1950) of Euarchontoglires and at least a more general pattern of placental mammals. However, body size also influences the available space in the nasal cavity and therefore may constrain the turbinal pattern. The absence of frontal sinuses in Scandentia would support this idea as this type of sinus is also absent or rudimentarily developed in many other small mammals (Paulli, 1900b, c; see Curtis and Van Valkenburgh, 2014a, for more details). Major differences in the turbinal pattern of the investigated Scandentia are related to the size and topography of the nasoturbinal, size and shape of frontoturbinal 2 and interturbinal (single or double scroll) and the formation of anterior processus of certain turbinals. The septoturbinal might be a synapomor- 


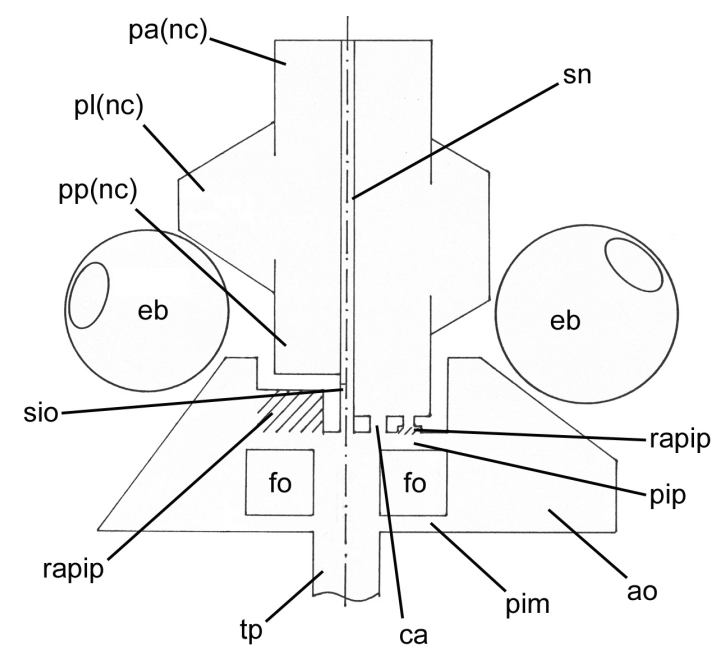

Figure 16. Schematic horizontal section of the fetal nasal capsule and basicranium of the orbitotemporal region of Tupaia (left) and Ptilocercus (right) to illustrate the arrangement of the septum interorbitale and adjacent structures that are influenced by orientation of the eye ball and orbit. Abbreviations: ao, ala orbitalis; ca, cartilago antorbitalis; eb, eye ball; fo, foramen opticum; nc, nasal capsule; pa, pars anterior; pim, pila metoptica; pip, pila praeoptica; $\mathrm{pl}$, pars lateralis; pp, pars posterior; rapip, radix anterior pilae praeopticae; sio, septum interorbitale; sn, septum nasi; tp, trabecular plate.

phic feature though it shows a different ontogenetic pattern in Ptilocercus and Tupaia.

Nevertheless, the ethmoidal region of Scandentia helps to elucidate the primate morphotype. The enigmatic aye-aye Daubentonia madagascariensis represents a basal clade of the Madagascan Strepsirhini, but its olfactory turbinal skeleton is by far the most complicated among primates (Maier, 1993b; Perelman et al., 2011; Roos et al., 2004; Maier and Ruf, 2014). It has three frontoturbinals and four interturbinals in the frontoturbinal recess as well as three ethmoturbinals and two interturbinals in the ethmoidal recess. However, all other primates have less complex nasal cavities, especially Platyrrhini (see Maier and Ruf, 2014). Thus the Daubentonia nasal pattern could be a highly derived character state as adaptation to its specialized foraging mode or it may represent a plesiomorphic pattern inherited from the ancestor of Euarchontoglires (Maier and Ruf, 2014). The latter hypothesis is supported by the fact that many basal placental mammals like Xenarthra and members of the clade Afrotheria have a significantly higher number of olfactory turbinals ranging from 4-5 frontoturbinals and 4-8 ethmoturbinals in xenarthrans (Paulli, 1900c; Reinbach, 1952a, b; Schneider, 1955) and 4-9 frontoturbinals and 4-13 ethmoturbinals in afrotherians (Paulli, 1900b; Stoessel et al., 2010). The number of interturbinals between fronto- and ethmoturbinals is extremely increased, especially in Proboscidea. Interestingly small- to medium-sized afrotherians show a lower number of olfactory turbinals, which resembles more or less the pat- tern observed in the presumed euarchontogliran morphotype. In Hyracoidea three frontoturbinals and three ethmoturbinals are present (Paulli, 1900c; Stoessel et al., 2010). Investigated members of the Afrosoricida have two frontoturbinals and three ethmoturbinals (Paulli, 1900c; Roux, 1947). Though most molecular phylogenies place Afrosoricida not at the base of the afrotherian clade (Murphy et al., 2001; Springer et al., 2003; Bininda-Emonds et al., 2007; Meredith et al., 2011), their number of turbinals could reflect a general placental pattern. Our new observations on Ptilocercus confirm the turbinal morphotype already presumed for Scandentia and in addition the hypothesis already preferred by Maier and Ruf (2014) - i.e. Daubentonia secondarily increased its number of turbinals.

\subsection{Septum interorbitale}

A septum interorbitale is generally present in "reptiles" and non-mammalian synapsids (Weber, 1927; Romer, 1956). Thus, these taxa have a tropibasic skull, i.e. a broad anterior skull base and widely separated orbits. According to Gaupp (1900) the formation of the septum interorbitale in reptiles and the mammalian ancestors is limited among other factors by the size and topography of the orbits as well as the small olfactory organ. During mammalian evolution the septum interorbitale becomes incorporated into the cupula nasi posterior due to the caudally expanding nasal cavity in addition to the intensive development of the telencephalon. Thus the septum interorbitale becomes part of the septum nasi and the cupula nasi posterior. The primarily tropibasic basicranium of microsmatic reptiles and basal synapsids becomes secondarily platybasic in macrosmatic mammals (Gaupp, 1900; Starck, 1979).

Concerning Euarchontoglires the distribution of a septum interorbitale across the major clades is puzzling. In Ptilocercidae the rostral portion of the primary basicranium forms a trabecular plate (Trabekelplatte) and therefore it is platybasic. Tupaiidae have a septum interorbitale and a tropibasic cranium. A comparative topography of the fetal nasal capsule and anterior basicranium of Ptilocercus and Tupaia is presented in Fig. 16. Several authors interpret the septum interorbitale of Tupaia as a primate character (Saban, 1957; Spatz, 1964; Starck, 1975) and thus a synapomorphy of Scandentia and Primates, because they were not aware of the pattern in Ptilocercus. Henckel (1928) did not observe a septum interorbitale in a $20 \mathrm{~mm}$ CRL fetus of Tupaia javanica. Hence, he separated Scandentia from Primates. However, this result was disproved by Zeller (1983), who described a distinct septum in the respective specimen. Many investigations have revealed that the septum interorbitale of primates shows a certain level of plasticity as a non-uniform morphological structure and thus resembles an equivocal character for systematic analyses of this order (Frets, 1914; Haines, 1950; Starck, 1953, 1960, 1975, 1979, 1984; Maier, 1983; Schneck, 1986). For instance, the septum interorbitale can 
be present only in certain ontogenetic stages as observed in Propithecus (Starck, 1962).

Absence of a septum interorbitale in Dermoptera is indicated by lack of this structure in a fetal Galeopithecus temmincki (now Galeopterus variegatus) (Henckel, 1929), but no data are available on adult stages. In contrast, many Rodentia and all investigated Lagomorpha have a septum interorbitale (e.g. Voit, 1909; Schrenk, 1989; Ruf, 2004, I. Ruf, personal observation, 2015); therefore a septum interorbitale might be a ground plan character of Glires.

Polarization of the septum interorbitale in terms of apomorphic versus plesiomorphic ground plan character states of euarchontogliran major clades depends on which phylogeny is applied and still remains ambiguous. Furthermore, the ontogenetic transformation of the anterior floor of the braincase has to be taken into account. In many moderate macrosmatic mammals (e.g. lemurs, Chiroptera, certain Eulipotyphla) the incorporation of the septum interorbitale in the nasal capsule is not complete and therefore a short septum interorbitale is still present, which resembles a primary septum interorbitale (plesiomorphy). In contrast mammals like higher primates, which have an evolved vision as a dominating sense and hence a reduced olfactory organ, show a reduction of the nasal capsule and therefore a recurrence of a septum interorbitale, which represents a secondary structure (apomorphy). The latter was already incorporated in the nasal capsule in their ancestors (Starck, 1979; Maier, 1983, 1986). Thus, not in all taxa does the septum interorbitale represent a primitive (plesiomorphic) mammalian feature.

In general frontal orientation of the orbits is assumed to be correlated with an arboreal lifestyle because the resulting stereoscopic vision supports fast climbing and jumping in a complex three-dimensional environment like a tree (Collins, 1921; Howells, 1947). However, many small nonprimate mammals exist that do not show such adaptations, e.g. tree squirrels (Cartmill, 1970, 1972). Therefore, Cartmill (1972) proposes that the orbital orientation in primates and tree shrews is exclusively constrained by stereoscopic vision used for optical control during foraging. There are conflicting hypotheses about the correlation of the orbit size and the existence of the septum interorbitale. According to Starck (1979) orbit size influences the development of a septum interorbitale whereas Spatz (1970) concludes that the frontal orientation of the orbit is the major constraint. However, in Ptilocercus the relatively large orbit and its frontal orientation results in the opposite pattern: a trabecular plate instead. Ontogenetic studies have shown that the development of the septum interorbitale is constrained by the adjustment and demand for space of adjacent structures. For example in prosimians we observe a similar pattern: Loris has a septum interorbitale whereas Indri is lacking this structure though its orbits are larger and more frontally oriented than in the former (Starck, 1953). According to Starck (1953) the pattern of Indri is correlated with the larger nasal cavity and telencephalon. The septum interorbitale of Saimiri is sig- nificantly increased and becomes perforated during postnatal ontogeny forming a fenestra interorbitalis (Maier, 1983).

The laterally oriented orbits of Tupaia resemble a plesiomorphic pattern of placental mammals and Scandentia. In contrast Ptilocercus is highly specialized in being strictly arboreal and having therefore frontally oriented eyes. Thus, against the background of the similarly sized nasal cavities of the investigated Scandentia and the septum interorbitale pattern among other Euarchontoglires, the proportion of the ethmoidal region and the occurrence of a septum interorbitale in Tupaia, which are influenced by the orientation of the orbits, represent plesiomorphic features of Tupaiidae and Scandentia in general. Ptilocercus has lost the septum interorbitale which is a derived and therefore autapomorphic character state of Ptilocercidae. Furthermore, in early ontogeny Ptilocercus shows a foramen supraseptale that also represents an autapomorphic character of the respective family.

In conclusion the new data on the comparative anatomy and ontogeny of the ethmoidal region in Scandentia reveals new insight into the understanding of primate evolution. This refers especially to the septum interorbitale. As already suggested by Zeller (1986b) the ethmoidal region of Scandentia can hardly be used for elucidating systematic relationships to the order Primates as to the many plesiomorphic characters of the former. However, our interpretation of the ontogeny of the posterior nasal capsule and of the occurrence of the septum interorbitale clearly shows that the septum interorbitale is most probably not a synapomorphy of Scandentia and Primates and therefore has evolved independently in both orders. For consideration of the septum interorbitale as a systematic and/or phylogenetic relevant feature, it is not sufficient to simply refer to the presence or absence of this structure. Only further detailed ontogenetic and morphological studies across all major clades of Euarchontoglires are necessary to clarify the primary or secondary nature of the septum interorbitale in the respective taxa as well as other transformations during ontogeny (e.g. loss of the septum).

Author contributions. All authors designed the project. S. Janßen and U. Zeller analysed the histological serial section of Ptilocercus, made the 3-D model and the drawings, and collected the data on the fetus. I. Ruf made the $\mu \mathrm{CT}$ scans and virtual 3-D reconstruction of the adult specimens and created the figures. I. Ruf and U. Zeller wrote the manuscript.

Acknowledgements. We thank F. Mayer, C. Funk, and K. Mahlow (Museum für Naturkunde Berlin) for CT scanning of the adult Ptilocercus lowii specimen. J. Eberhardt (Senckenberg Frankfurt) helped with the figures. We also thank M. T. Silcox and an anonymous reviewer for helpful comments which served to improve the manuscript. The research on the adult Tupaia has been supported by Deutsche Forschungsgemeinschaft DFG (German Research Foundation) to I. Ruf (DFG RU 1496/4-1). 
Edited by: E. Fuchs

Reviewed by: M. Silcox and one anonymous referee

\section{References}

Berta, A., Ekdale, E. G., and Cranford, T. W.: Review of the cetacean nose: form, function, and evolution, Anat. Record, 297, 2205-2215, 2014.

Bininda-Emonds, O. R. P., Cardillo, M., Jones, K. E., MacPhee, R. D. E., Beck, R. M. D., Grenyer, R., Price, S. A., Vos, R. A., Gittleman, J. L., and Purvis, A.: The delayed rise of present-day mammals, Nature, 446, 507-512, 2007.

Born, G.: Die Plattenmodelliermethode, Arch. Mikr. Anat., 22, 584-599, 1883.

Broman, I.: Über die Entwicklung der konstanten grösseren Nasenhöhlendrüsen der Nagetiere, Z. Anat. Entwicklungs., 60, 439586, 1921.

Cartmill, M.: The orbits of arboreal mammals: a reassessment of the arboreal theory of primate evolution, $\mathrm{PhD}$ thesis, University of Chicago, 1970.

Cartmill, M.: Arboreal adaptations and the origin of the order Primates, in: The functional and evolutionary biology of pimates, edited by: Tuttle, R., Aldine-Atherton, Chicago, 97-122, 1972.

Clifford, A. B. and Witmer, L. M.: Case studies in novel narial anatomy: 3. Structure and function of the nasal cavity of saiga (Artiodactyla: Bovidae: Saiga tatarica), J. Zool. Lond., 264, 217-230, 2004.

Collins, E. T.: Changes in the visual organs correlated with the adoption of arboreal life and with the assumption of the erect posture, T. Ophthal. Soc. UK, 41, 10-90, 1921.

Craven, B. A., Neuberger, T., Paterson, E. G., Webb, A. G., Josephson, E. M., Morrison, E. E., and Settles, G. S.: Reconstruction and morphometric analysis of the nasal airway of the $\operatorname{dog}(\mathrm{Ca}$ nis familiaris) and implications regarding olfactory airflow, Anat. Rec., 290, 1325-1340, 2007.

Craven, B. A., Paterson, E. G., and Settles, G. S.: The fluid dynamics of canine olfaction: unique nasal airflow patterns as an explanation of macrosmia, J. R. Soc. Interface, 7, 933-943, 2010.

Curtis, A. A. and Van Valkenburgh, B.: Beyond the sniffer: frontal sinuses in Carnivora, Anat. Record, 297, 2047-2064, 2014.

de Beer G.: The development of the skull of the shrew, Philos. T. R. Soc. B, 217, 411-480, 1929.

Eiting, T. P., Smith, T. D., and Dumont, E. R.: Olfactory epithelium in the olfactory recess: a case study in New World leaf-nosed bats, Anat. Record, 297, 2105-2112, 2014.

Epple, G., Belcher, A. M., Küderling, I., Zeller, U., Scolnick, L., Greenfield, K. L., and Smith, A. B.: Making sense out of scents: species differences in scent glands, scent-marking behavior, and scent-mark composition in the Callitrichidae, in: Marmosets and Tamarins. Systematics, Behaviour, and Ecology, edited by: Rylands, A. B., Oxford University Press, Oxford, 123-151, 1993.

Frets, G. P.: Beiträge zur vergleichenden Anatomie und Embryologie der Nase der Primaten. III. Die Regio ethmoidalis des Primordialcraniums mit Deckknochen von einigen Catarrhinen, Prosimiae und anderen Menschen, Morpholog. Jb., 48, 239-279, 1914.

Frick, H. and Heckmann, U.: Ein Beitrag zur Morphogenese des Kaninchenschädels, Acta Anat., 24, 268-314, 1955.
Funke, C. and Kuhn, H.-J.: The morphogenesis of the arteries of the pelvic extremity: A comparative study of mammals with special reference to the tree shrew Tupaia belangeri (Tupaiidae, Scandentia, Mammalia), Adv. Anat. Embryol., 144, 1-97, 1998.

Gaupp, E.: Das Chondrocranium von Lacerta agilis, Ein Beitrag zum Verständnis des Amniotenschädels, Anat. Hefte, 15, 433595, 1900.

Haines, R. W.: The Interorbital Septum in Mammals, J. Linn. Soc. London, 16, 585-607, 1950.

Helgen, K. M.: Order Scandentia, in: Mammals of the World: A Taxonomic and Geographic Reference, edited by: Wilson, D. E. and Reeder, D. M., 3rd Edn., Johns Hopkins University Press, Baltimore, 104-109, 2005.

Henckel, K. O.: Das Primordialcranium von Tupaia und der Ursprung der Primaten, Z. Anat. Entw.-Gesch., 86, 204-227, 1928.

Henckel, K. O.: Die Entwicklung des Schädels von Galepithecus temmincki Waterh. und ihre Bedeutung für die stammesgeschichtliche und systematische Stellung der Galeopithecidae, Morphol. Jb., 62, 179-202, 1929.

Hennig, W.: Grundzüge einer Theorie der Phylogenetischen Systematik, Deutscher Zentralverlag, Berlin, 1950.

Hillenius, W. J.: The evolution of nasal turbinates and mammalian endothermy, Paleobiology, 18, 17-29, 1992.

Hofer, H.: Über das Spitzhörnchen, Natur. Volk., 87, 145-155, 1957.

Howells, W. W.: Mankind so far, Doubleday, Garden City, New York, 1947.

Janßen, S.: Beitrag zur Ontogenese und Morphologie des Craniums von Ptilocercus owii (Mammalia: Scandentia: Tuapiidae), MD thesis, Georg-August-Universität Göttingen, Germany, 89 pp., 1993.

Kemp, T. S.: The origin of mammalian endothermy: a paradigm for the evolution of a complex biological structure, Zool. J. Linn. Soc., 147, 473-488, 2006.

Klima, M.: Development of the cetacean nasal skull, Adv. Anat. Embryol. Cell. Biol., 149, 1-143, 1999.

Kuhn, H.-J.: Die Entwicklung und Morphologie des Schädels von Tachyglossus aculeatus, Abh. Senckenb. Naturforsch. Ges., 528, 1-192, 1971.

Kuhn, H.-J. and Liebherr, G.: The early development of the epicardium in Tupaia belangeri, Anat, Embryol., 177, 225-234, 1988.

Kuhn, H.-J. and Schwaier, A.: Implantation, early placentation, and the chronology of embryogenesis in Tupaia belangeri, Z. Anat. Entwicklungs., 142, 315-340, 1973.

Kuhn, H. J. and Zeller, U.: Morphogenesis of the mammalian skull, Mammalia depicta 13, Parey Verlag, Hamburg, 1987.

Le Gros Clark, W. E.: On the skull of Tupaia, P. Zool. Soc. Lond., 1925, 559-567, 1925.

Le Gros Clark, W. E.: On the anatomy of the pen-tailed tree shrew (Ptilocercus lowii), P. Zool. Soc. Lond., 1926, 1179-1309, 1926.

Le Gros Clark, W. E.: The projection of the olfactory epithelium on the olfactory bulb in the rabbit, J. Neurol. Neurosurg. Ps., 14, $1-10,1951$.

Lyon Jr., M. W.: Treeshrews: an account of the mammalian family Tupaiidae, Proc. US Natl. Mus., 45, 1-188, 1913.

Macrini, T. E.: Comparative morphology of the internal nasal skeleton of adult marsupials based on X-ray computed tomography, B. Am. Mus. Nat. Hist., 365, 1-91, 2012. 
Maier, W.: Nasal structures in old and new world primates, in: Evolutionary Biology of the New World Monkeys and Continental Drift, edited by: Ciochon, R. L. and Chiarelli, A. B., Plenum Press, New York, London, 219-241, 1980.

Maier, W.: Morphology of the interorbital region of Saimiri sciureus, Folia Primatol., 41, 277-303, 1983.

Maier, W.: Functional principles of the growing skull of primates as shown by the posterior cupula of the nasal capsule, in: Définition et origines de l'home, edited by: Sakka, M., CNRS, Paris, 199207, 1986.

Maier, W.: Aspects of ontogenetic development of nasal and facial skeletons in Primates, in: Craniofacial Abnormalities and Clefts of the Lip, edited by: Pfeifer, G., Alveolus and Palate, Thieme Stuttgart, 115-123, 1991.

Maier, W.: Cranial morphology of the therian common ancestor, as suggested by the adaptations of neonate marsupials, in: Mammal phylogeny: mesozoic differentiation, multituberculates, monotremes, early therians, and marsupials, edited by: Szalay, F. S., Novacek, M. J., and McKenna, M. C., Springer, New York, 165-181, 1993a.

Maier, W.: Zur evolutiven und funktionellen Morphologie des Gesichtsschädels der Primaten, Z. Morphol. Anthropol., 79, 279-299, 1993b.

Maier, W. and Ruf, I.: Morphology of the nasal capsule of Primates - with special reference to Daubentonia and Homo, Anat. Record, 297, 1985-2006, 2014.

McKenna, M. C. and Bell, S. K.: Classification of Mammals above the Species Level, Columbia University Press, New York, 1997.

Meredith, R. W., Janečka, J. E., Gatesy, J., Ryder, O. A., Fisher, C. A., Teeling, E. C., Goodbla, A., Eizirik, E., Simão, T. L. L., Stadler, T., Rabosky, D. L., Honeycutt, R. L., Flynn, J. J., Ingram, C. M., Steiner, C., Williams, T. L., Robinson, T. J., Burk-Herrick, A., Westerman, M., Ayoub, N. A., Springer, M. S., and Murphy, W. J.: Impacts of the Cretaceous terrestrial revolution and $\mathrm{KPg}$ extinction on mammal diversification, Science, 334, 521-524, 2011.

Murphy, W. J., Eizirik, E., O’Brien, S. J., Madsen, O., Scally, M., Douady, C. J., Teeling, E., Ryder, O. A., Stanhope, M. J., de Jong, W. W., and Springer, M. S.: Resolution of the early placental mammal radiation using Bayesian phylogenetics, Science, 294, 2348-2351, 2001.

Negus, V.: The Comparative Anatomy and Physiology of the Nose and Paranasal Sinuses, E. \& S. Livingston Ltd., Edinburgh and London, 1958.

Nishihara, H., Masami Hasegawa, M., and Okada, N.: Pegasoferae, an unexpected mammalian clade revealed by tracking ancient retroposon insertions, P. Natl. Acad. Sci. USA, 103, 9929-9934, 2006.

O’Leary, M. A., Bloch, J. I., Flynn, J. J., Gaudin, T. J., Giallombardo, A., Giannini, N. P., Goldberg, S. L., Kraatz, B. P., Luo, Z.-X., Meng, J., Ni, X., Novacek, M. J., Perini, F. A., Randall, Z. S., Rougier, G. W., Sargis, E. J., Silcox, M. T., Simmons, N. B., Spaulding, M., Velazco, P. M., Weksler, M., Wible, J. R., and Cirranello, A. L.: The placental mammal ancestor and the postK-Pg radiation of placentals, Science, 339, 662-667, 2013.

Olson, L. E., Sargis, E. J., and Martin, R. D.: Intraordinal phylogenetics of tree shrews (Mammalia: Scandentia) based on evidence from the mitochondrial 12S rRNA gene, Mol. Phylogenet. Evol., 35, 656-673, 2004.
Paulli, S.: Über die Pneumaticität des Schädels bei den Säugetieren. Eine morphologische Studie. I. Über den Bau des Siebbeins. Über die Morphologie des Siebbeins und die Pneumaticität bei den Monotremen und den Marsupialiern, Morph. Jb., 28, 147178, 1900a.

Paulli, S.: Über die Pneumaticität des Schädels bei den Säugetieren. Eine morphologische Studie. II. Über die Morphologie des Siebbeins und die Pneumaticität bei den Ungulaten und Probosciden, Morph. Jb., 28, 179-251, 1900b.

Paulli, S.: Über die Pneumaticität des Schädels bei den Säugetieren. Eine morphologische Studie. III. Über die Morphologie des Siebbeins und die Pneumaticität bei den Insectivoren, Hyracoideen, Chiropteren, Carnivoren, Pinnipedien, Edentaten, Rodentiern, Prosimiern und Primaten, nebst einer zusammenfassenden Übersicht über die Morphologie des Siebbeins und die der Pneumaticität des Schädels bei den Säugetieren, Morph. Jb., 28, 483-564, 1900c.

Perelman, P., Johnson, W. E., Roos, C., Seuanez, H. N., Horvath, J. E., Moreira, M. A. N., Kessing, B., Pontius, J., Roelke, M., Rumpler, Y., Schneider, M. P. C., Silva, A., O’Brien, S. J., and Pecon-Slattery, J.: A molecular phylogeny of living primates, PLOS Genet., 7, 1-17, 2011.

Reinbach, W.: Zur Entwicklung des Primordialcraniums von Dasypus novemcinctus Linne (Tatusia novemcincta LESSON), Teil I, Z. Morphol. Anthropol., 44, 375-444, 1952a.

Reinbach, W.: Zur Entwicklung des Primordialcraniums von Dasypus novemcinctus Linne (Tatusia novemcincta LESSON), Teil II, Z. Morphol. Anthropol., 45, 1-72, $1952 b$.

Roberts, T. R., Lanier, H. C., Sargis, E. J., and Olson, L. E.: Molecular phylogeny of treeshrews (Mammalia: Scandentia) and the timescale of diversification in Southeast Asia, Mol. Phylogenet. Evol., 60, 258-372, 2011.

Romer, A. S.: Osteology of the reptiles, The University of Chicago Press, Chicago, 1956.

Roos, C., Schmitz, J., and Zischler, H.: Primate jumping genes elucidate strepsirhine phylogeny, P. Natl. Acad. Sci. USA, 101, 10650-10654, 2004.

Roux, G.: The cranial development of certain Ethiopian "insectivores" and its bearing on the mutual affinities of the group, Acta Zool., 28, 165-397, 1947.

Rowe, T. B., Eiting, T. P., Macrini, T. E., and Ketcham, R. A.: Organization of the olfactory and respiratory skeleton in the nose of the gray short-tailed opossum Monodelphis domestica, J. Mamm. Evol., 12, 303-336, 2005.

Ruf, I.: Vergleichend-ontogenetische Untersuchungen an der Ethmoidalregion der Muroidea (Rodentia, Mammalia). Ein Beitrag zur Morphologie und Systematik der Nagetiere, Dissertation, Universität Tübingen, available at: http://www.nbn-resolving.de/ urn:nbn:de:bsz:21-opus-13618 (last access: 5 September 2015), 1-301, 2004.

Ruf, I.: Comparative anatomy and systematic implications of the turbinal skeleton in Lagomorpha (Mammalia), Anat. Record, 297, 2031-2046, 2014.

Ruf, I., Maier, W., Rodrigues, P. G., and Schultz, C. L.: Nasal anatomy of the nonmammaliaform cynodont Brasilitherium riograndensis (Eucynodontia, Therapsida) reveals new insight into mammalian evolution, Anat. Record, 297, 2018-2030, 2014. 
Saban, R.: Les affinités du genre Tupaia Raffles 1821, d'après les caractères morphologiques de la tête osseuse, A. Palaeontol., 43, 1-44, 1957.

Sargis, E. J.: The grasping behaviour, locomotion and substrate use of the tree shrews Tupaia minor and T. tana (Mammalia, Scandentia), J. Zool. Lond., 253, 485-490, 2001.

Sargis, E. J.: The postcranial morphology of Ptilocercus lowii (Scandentia, Tupaiidae) and its implications for primate supraordinal relationships, in: Primate Origins: Adaptations and Evolution, edited by: Ravosa, M. J. and Dagosto, M., Springer, New York, 51-82, 2007.

Schneck, G. H.: Some aspects of the development of the orbitotemporal region in hominoid primates, in: Selected Proceedings of the Tenth Congress of the Interantional Primatological Society, Nairobi, Kenya, 1984, Vol. 1, Primate evolution, edited by: Else, J. G. and Lee, P. C., Cambridge University Press, Cambridge, 265-271, 1986.

Schneider, R.: Zur Entwicklung des Chondrocraniums von Bradypus, Morph. Jahrb., 95, 209-301, 1955.

Schrenk, F.: Zur Schädelentwicklung von Ctenodactylus gundi (ROTHMANN 1776) (Mammalia: Rodentia), Cour. Forsch.-Inst. Senckenberg, 108, 1-241, 1989.

Smith, T. D., Bhatnagar, K. P., Rossie, J. B., Docherty, B. A., Burrows, A. M., Cooper, G. M., Mooney, M. P., and Siegel, M. I.: Scaling of the first ethmoturbinal in nocturnal strepsirrhines: olfactory and respiratory surfaces, Anat. Record, 290, 215-237, 2007.

Smith, T. D., Eiting, T. P., Bonar, C. J., and Craven, B. A.: Nasal morphometry in marmosets: loss and redistribution of olfactory surface area, Anat. Record, 297, 2093-2104, 2014a.

Smith, T. D., Laitman, J. T., and Bhatnagar, K. P.: The shrinking anthropoid nose, the human vomeronasal organ, and the language of anatomical reduction, Anat. Record, 297, 2196-2204, 2014b.

Spatz, W.: Beitrag zur Kenntnis der Ontogenese des Cranium von Tupaia glis (DIARD 1820), Morph. Jb., 106, 321-416, 1964.

Spatz, W.: Binokuläres Sehen und Kopfgestaltung: Ein Beitrag zum Problem des Gestaltwandels des Schädels der Primaten, insbesondere der Lorisidae, Acta Anat., 75, 489-520, 1970.

Springer, M. S., Murphy, W. J., Eizirik, E., and O'Brien, S. J.: Placental mammal diversification and the Cretaceous-Tertiary boundary, P. Natl. Acad. Sci. USA, 100, 1056-1061, 2003.

Starck, D.: Morphologische Untersuchungen am Kopf der Säugetiere, besonders der Prosimier - ein Beitrag zum Problem des Formwandels des Säugerschädels, Z. Wiss. Zool., 157, 169219, 1953.

Starck, D.: Das Cranium eines Schimpansenfetus (Pan troglodytes, BLUMENBACH 1799) von $71 \mathrm{~mm}$ Scheitel-Steißlänge, nebst Bemerkungen über die Körperform von Schimpansenfeten, Morph. Jb., 100, 559-647, 1960.

Starck, D.: Das Cranium von Propithecus spec. (Prosimiae, Lemuriformes, Indriidae), (Beiträge zur Kenntnis des PrimatenCraniums III), Biblioth. Primatol. (Schultz-Festschrift), 1, 163196, 1962.

Starck, D.: The development of the chondrocranium in primates, in: Phylogeny of the Primates. A multidisciplinary approach, edited by: Luckett, W. P. and Szalay, F. S., Plenum Press, New York, London, 127-155, 1975.
Starck, D.: Vergleichende Anatomie der Wirbeltiere auf evolutionsbiologischer Grundlage, Band 2, Springer, Berlin, Heidelberg, New York, 1979.

Starck, D.: The nasal cavity and nasal skeleton of Tarsius, in: Biology of tarsiers, edited by: Niemitz, C., Fischer, Stuttgart, 275290, 1984.

Stoessel, A., Junold, A., and Fischer, M. S.: The morphology of the eutherian ethmoidal region and its implications for higher-order phylogeny, J. Zool. Syst. Evol. Res., 48, 167-180, 2010.

Van Valkenburgh, B., Theodor, J., Friscia, A., Pollack, A., and Rowe, T.: Respiratory turbinates of canids and felids: a quantitative comparison, J. Zool., 264, 281-293, 2004.

Van Valkenburgh, B., Curtis, A., Samuels, J. X., Bird, D., Fulkerson, B., Meachen-Samuels, J., and Slater, G. J.: Aquatic adaptations in the nose of carnivorans: evidence from the turbinates, J. Anat., 218, 298-310, 2011.

Van Valkenburgh, B., Smith, T. D., and Craven, B. A.: Tour of a labyrinth: exploring the vertebrate nose, Anat. Record, 297, 1975-1984, 2014a.

Van Valkenburgh, B., Pang, B., Bird, D., Curtis, A., Yee, K., Wysocki, C., and Craven, B. A.: Respiratory and olfactory turbinals in filiform and caniform carnivorans: the influence of snout length, Anat. Record, 297, 2065-2079, 2014b.

Voit, M.: Das Primordialcranium des Kaninchens unter Berücksichtigung der Deckknochen, Anat. Hefte, 38, 425-616, 1909.

Weber, M.: Die Säugetiere. Einführung in die Anatomie und Systematik der recenten und fossilen Mammalia, Band 1, 2nd Edn., Gustav Fioscher Verlag, Jena, 1927.

Wible, J. R.: The ear region of the pen-tailed treeshrew, Ptilocercus lowii Gray, 1848 (Placentalia, Scandentia, Ptilocercidae), J. Mamm. Evol., 16, 199-233, 2009.

Wible, J. R.: On the treeshrew skull (Mammalia, Placentalia, Scandentia), Ann. Carnegie Mus., 79, 149-230, 2011.

Wible, J. R. and Zeller, U.: Cranial circulation of the pen-tailed tree shrew Ptilocercus lowii and relationships of Scandentia, J. Mammal. Evol., 2, 209-230, 1994.

Wilson, D. E.: Order Scandentia, in: Mammal Species of the World: A Taxonomic and Geographic Reference, edited by: Wilson, D. E. and Reeder, D. M., 2nd Edn., Smithsonian Institution, Washington, 131-133, 1993.

Zeller, U.: Zur Ontogenese und Morphologie des Craniums von Tupaia belangeri (Tupaiidae, Scandentia, Mammalia), MD thesis, Georg-August-Universität Göttingen, Germany, 1983.

Zeller, U.: Morphogenesis of the mammalian skull with special reference to Tupaia, in: Mammalia depicta, edited by: Kuhn, A. J. and Zeller, U., 13, Beih. Z. Säugetierk., 17-50, 1987.

Zeller, U. A.: Ontogeny and cranial morphology of the tympanic region of the Tupaiidae, with special reference to Ptilocercus, Folia Primatol., 47, 61-80, 1986a.

Zeller, U. A.: The systematic relations of tree shrews: evidence from skull morphogenesis, in: Selected Proceedings of the Tenth Congress of the Interantional Primatological Society, Nairobi, Kenya, 1984, Vol. 1, Primate evolution, edited by: Else, J. G. and Lee, P. C., Cambridge University Press, Cambridge, 273-280, $1986 b$. 